\title{
Moonlighting Proteins and Protein-Protein Interactions as Neurotherapeutic Targets in the G Protein-Coupled Receptor Field
}

\author{
Kjell Fuxe ${ }^{\star, 1}$, Dasiel O Borroto-Escuela1, Wilber Romero-Fernandez' ${ }^{1}$, Miklós Palkovits ${ }^{2}$, \\ Alexander O Tarakanov ${ }^{3}$, Francisco Ciruela ${ }^{4}$ and Luigi F Agnati ${ }^{5}$ \\ ${ }^{1}$ Department of Neuroscience, Karolinska Institutet, Stockholm, Sweden; ${ }^{2}$ Department of Anatomy, Histology and \\ Embryology, Hungarian Academy of Sciences and Semmelweis University, Budapest, Hungary; ${ }^{3}$ Russian Academy of \\ Sciences, St. Petersburg Institute for Informatics and Automation, Saint Petersburg, Russia; ${ }^{4}$ Facultat de Medicina, \\ Departament de Patologia i Terapèutica Experimental IDIBELL-Universitat de Barcelona, L'Hospitalet de Llobregat, Unitat \\ de Farmacologia, Barcelona, Spain; ${ }^{5}$ IRCCS, Lido Venice, Italy
}

\begin{abstract}
There is serious interest in understanding the dynamics of the receptor-receptor and receptor-protein interactions in space and time and their integration in GPCR heteroreceptor complexes of the CNS. Moonlighting proteins are special multifunctional proteins because they perform multiple autonomous, often unrelated, functions without partitioning into different protein domains. Moonlighting through receptor oligomerization can be operationally defined as an allosteric receptor-receptor interaction, which leads to novel functions of at least one receptor protomer. GPCR-mediated signaling is a more complicated process than previously described as every GPCR and GPCR heteroreceptor complex requires a set of $G$ protein interacting proteins, which interacts with the receptor in an orchestrated spatio-temporal fashion. GPCR heteroreceptor complexes with allosteric receptor-receptor interactions operating through the receptor interface have become major integrative centers at the molecular level and their receptor protomers act as moonlighting proteins. The GPCR heteroreceptor complexes in the CNS have become exciting new targets for neurotherapeutics in Parkinson's disease, schizophrenia, drug addiction, and anxiety and depression opening a new field in neuropsychopharmacology. Neuropsychopharmacology Reviews (2014) 39, I31-155; doi: 10.1 038/npp.2013.242; published online 9 October 2013
\end{abstract}

Keywords: receptor-receptor interactions; G protein-coupled receptors; moonlighting; heterodimerization; neurotherapeutic targets; neuropsychiatric disorders

\section{INTRODUCTION}

The focus of this review will be the special case of protein-protein interactions among receptors, especially GPCRs which results in the formation of heteroreceptor complexes in the CNS (see below). Lefkowitz has made the epoch making discoveries in the GPCR field. It started already in 1970 and the breakthrough came in 1986 when Lefkowitz and his group cloned the gene and cDNA for the beta2 adrenergic receptor and showed its homology with the rhodopsin sequence, which led to the discovery of the GPCR superfamily (Dixon et al, 1986; Lefkowitz, 2000).

Jeffery introduced the concept of moonlighting proteins in 1999 (Jeffery, 1999). Such proteins are special multifunctional proteins because they perform multiple autonomous, often

${ }^{*}$ Correspondence: Professor K Fuxe, Department of Neuroscience, Karolinska Institutet, Retzius väg 8, 17177, Stockholm, Sweden, Tel: +46 8 52487077, Fax: +46 8 315721, E-mail: Kjell.Fuxe@ki.se Received 18 February 2013; revised 4 July 2013; accepted 5 July 2013; accepted article preview online 6 September 2013 unrelated, functions without partitioning into different protein domains. Thus, moonlighting proteins represent an interesting category of multifunctional proteins in which two or more functions can be found in a single-polypeptide chain. Jeffrey (2004) defined the term as: moonlighting proteins are proteins with more than one function, but do not include proteins where the multiple functions result from different RNA splice variants, gene fusions or several homologous proteins (isoforms) (Jeffery, 2004).

The existence of such proteins was reported roughly 20 years ago. It was found that certain structural proteins like crystallins, water-soluble structural proteins in the lens of the eye, are evolving and developed from metabolic enzymes (Huberts and van der Klei, 2010). A number of mechanisms have been proposed for the change of functions in a moonlighting protein (Jeffery, 1999), like different locations within a cell, intracellular versus extracellular location, presence in different cell types, binding of a substrate or cofactor including existence of different binding sites for different substrates, homomerization of the 
protein and formation of complexes with other proteins (heteroprotein complexes) (Jeffery, 1999).

It was recently proposed (Gancedo and Flores, 2008) that the moonlighting phenomenon is a consequence of the Jacob's principle, namely of the tinkerer's capability of performing evolution (Jacob, 1977), which means that novel functions can be carried out by adapting the existing devices. The concept of moonlighting proteins has now been introduced in the field of GPCR heteroreceptor complexes (Borroto-Escuela et al, 2011b). Moonlighting of receptors through heteromerization is in the current review operationally defined to take place when the allosteric receptor-receptor interactions lead to novel functions of at least one receptor protomer.

\section{METHODS FOR STUDYING PROTEIN-PROTEIN INTERACTIONS}

The uncovering of receptor-receptor interactions (that is, GPCR oligomerization) has been assessed through a plethora of methodologies which run from classical biochemical approaches to biophysical techniques. Indeed,
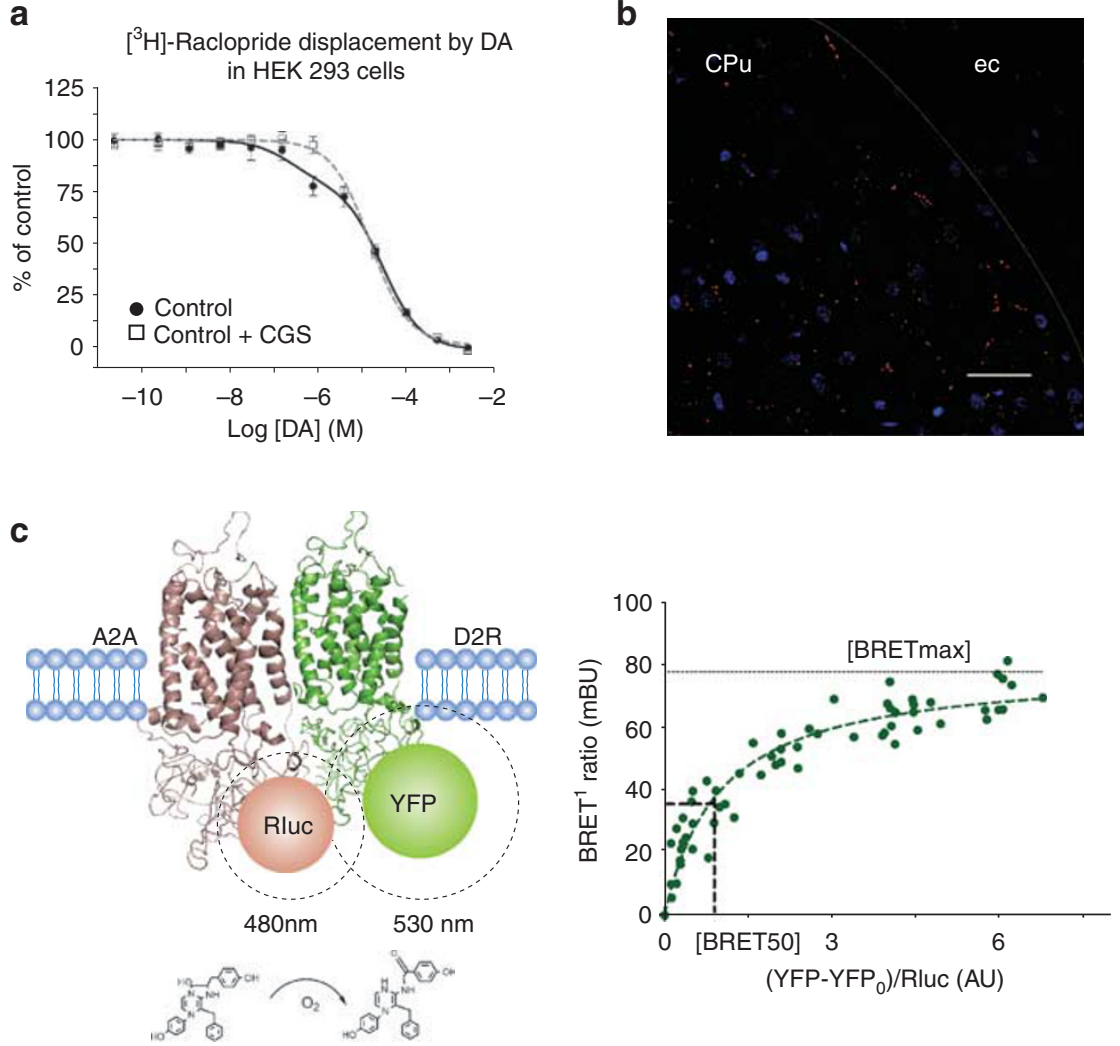

Figure 1. Different methods have been used to study GPCR homo and heteroreceptor complexes. As examples are shown methods used to study the existence of A2A-D2 heteroreceptor complexes in heterologous expression systems and in brain ex vivo. (a) Competition experiments using $\mathrm{D}_{2}$-like receptor antagonist $\left[{ }^{3} \mathrm{H}\right]$-Raclopride $(2 \mathrm{nM})$ versus increasing concentrations of dopamine in transiently cotransfected HEK293T cell membranes. Panel (a) illustrates the right shift of the competition curve after treatment with the A2A agonist CGS21680 in the high affinity range of the D2R agonist binding site, which demonstrates a reduction of D2R affinity in the high affinity state. (b) Detection of A2A-D2 heteroreceptor complexes in ex vivo brain sections can be found by in situ proximity ligation assay (PLA). PLA-positive A2A-D2 heteroreceptor complexes in striatal sections have been visualized as red clusters (blobs, dots) within the neuropil of caudate putamen (CPu), which were almost absent within the external capsule (ec). (c) In $\mathrm{C}$ the principle of the $B R E T^{1}$ method is illustrated giving strong support for the existence of A2AR-D2R heteromers. In the presence of $h$-coelenterazine, an energy transfer between Rluc and YFP occurs when the distance between them is less than $100 \AA$. To the right a BRET ${ }^{1}$ saturation curve for the A2A-D2 hetero receptor complex (D2LR ${ }^{\text {Rluc }}+$ A2AR ${ }^{\text {YFP }}$, filled circles) is shown giving BRET max and BRET EC50 values. 
(eg, coimmunolocalization) and immobilized proteinprotein interaction assays (eg, coimmunoprecipitation). Again these approaches fail to provide unambiguous evidence for direct receptor-receptor interactions. In addition, their invasive nature still has disadvantages as false results were obtained due to the hydrophobic nature of receptors. Nevertheless, besides the inherent technical problems associated with these methods, they have proven to be very useful in initially confirming potential interactions between different GPCRs. Interestingly, to overcome the invasive nature of the immobilized protein-protein interaction assays, a set of fluorescence-based technologies have been developed. Some of these approaches are based on the resonance energy transfer (RET) principle (Figure 1c) and use receptor constructs which bear genetically fused 'donor' and 'acceptor' chromophores (Figure 1c). The bioluminescence-RET (BRET) approach involves an enzyme as a donor (eg, renilla luciferase, Rluc) which upon substrate oxidation generates bioluminescence engaging in a RET process with the appropriate acceptor molecule (eg, yellow fluorescent protein, YFP) provided they are in close proximity $(<10 \mathrm{~nm}$ ) (Figure 1c). Similarly, fluorescence-RET (FRET) techniques use a pair of fluorophores as donor and acceptor molecules (eg, cyan fluorescent protein, CFP and YFP). Thus, upon donor excitation with the matching monochromatic light the acceptor fluorophore can absorb resonant energy, if in close proximity. Overall, these experiments have favored the possibility of carrying out 'in cell' dynamic experiments. Therefore, the use of the previously mentioned RET-based techniques has emerged as a powerful tool in the study of GPCR oligomerization in living cells. However, it is important to keep in mind that there are several inherent problems associated with the use of these RET-based techniques. For instance, the attachment of such large chromophore proteins may preclude proper receptor function, which makes the interpretation of results difficult. In addition, the existence of false RET signals produced by photophysic cross-talks should be considered. Finally, an increase of non-specific RET can take place as a result of the random collision of intracellularly accumulated RET-tagged receptors when transiently overexpressed. As such, some controversy surrounds these approaches (Bouvier et al, 2007; James et al, 2006). Nevertheless, when RET-based results are properly assessed the elegant demonstration of dynamic oligomerization of ectopically expressed GPCRs and of cells from transgenic mice is possible (Audet et al, 2010; Marullo and Bouvier, 2007; Pin et al, 2007). There is consensus that RET methods strongly support the existence of receptor heteromers in living cells (Ferre et al, 2009). However, their existence in the CNS still remains a challenge but brain heteroreceptor complexes have been detected (see below) (Borroto-Escuela et al, 2013).

The demonstration of the existence of higher-order oligomers in living cells appears possible thanks to the combination of two fluorescence-based techniques. The detection of complexes containing metabotropic glutamate receptor 5 (mGlu5R), adenosine $\mathrm{A} 2 \mathrm{~A}$ receptor (A2AR) and dopame $\mathrm{D} 2$ receptor (D2R) may be achieved by combining the bimolecular fluorescence complementation (BiFC) technique with the BRET approach (Cabello et al, 2009). In brief, a fluorescence signal is created when two nonfluorescent fragments of a fluorescent protein (eg, YFP) when brought in close proximity by a receptor heterodimer (eg, mGlu5R/D2RYFP), allowing this reconstituted fluorescent protein to act as an acceptor fluorophore in a BRET process (eg, A2ARRluc-mGlu5R/D2RYFP). Indeed, by means of this BiFC/BRET approach it is possible to demonstrate the likely formation of A2AR-mGlu5R-D2R heteroreceptor complexes in cultured cells. Interestingly, by using triple-labeling post-embedding immunogold and detection at the electron microscopic level, the precise codistribution of these receptors in the extrasynapatic plasma membrane of glutamate synapses of the striatopallidal GABA neurons is achieved (Cabello et al, 2009). As such, it can be hypothesized that an A2AR-mGlu5R-D2R heteroreceptor complex exists in the striatum.

The sequential BRET-FRET technique is also developed specifically for the potential identification of higher-order heteroreceptor complexes in living cells, including the CB1D2-A2A heteroreceptor complex (Carriba et al, 2008). Through a combination of BRET and FRET, results are obtained consistent with the existence of this higher-order heteroreceptor complex. This observation is in line with the indications for the existence of striatal CB1-D2 heteroreceptor complexes obtained in previous work on the brain (Fuxe et al, 2010; Marcellino et al, 2008). This higher-order heteroreceptor complex is an integrator of DA, adenosine, and endocannabinoid signals. Through a combined bioluminescence/fluorescence complementation and energy transfer, several dopamine D2 receptors have also been located in close molecular proximity in living mammalian cells, consistent with their organization as higher-order dimers at the plasma membrane (Guo et al, 2008).

Overall, the RET and BiFC assays have inherent drawbacks mainly associated with the dependence of the ectopical expression of a fluorescent protein-fusion receptor, which may not necessarily behave exactly as their native counterparts. In addition, these assays include the risk of generating overexpression-mediated artificial receptor complexes. Therefore, the future of these techniques will rely on their ability to successfully detect native receptor oligomers, which has been accomplished with time-resolved FRET between GPCR ligands (Albizu et al, 2010), but high levels of receptor expression appears necessary.

The detection of native striatal A2AR-D2R heteroreceptor complexes has been achieved by means of another fluorescence-based approach, the protein ligation assay (Trifilieff et al, 2011; Borroto-Escuela et al, 2013). The PLA technique involves the use of two specific primary antibodies against the receptors being studied (ie, D2R and A2AR). The pair of secondary antibodies bears complementary oligonucleotides, which upon close proximity, usually a maximum of $16 \mathrm{~nm}$ between secondary antibodies, anneal into a circular dsDNA molecule. This 
serves as a template for rolling circle amplification, resulting in a long single-stranded rolling circle product attached to one of the proximity probes. As the rolling circle product is linked to the proximity probe, it is attached at the site where the proximity probe bound and the location of the heteroreceptor complex is revealed (Borroto-Escuela et al, 2010a; Romero-Fernandez et al, 2012; Soderberg et al, 2006; Trifilieff et al, 2011; Borroto-Escuela et al, 2013). The rolling circle products can then be detected and quantified by hybridizing fluorescent oligonucleotides to the repeated sequences of the rolling circle products which render them visible by fluorescence microscopy. This makes it possible to study the localization and modulation of brain heteroreceptor complexes as fixed tissue is used. The PLA signal is influenced by the length of the oligonucleotides linked to the secondary antibodies. It is important to mention here that the main drawback of this technique lies in obtaining specific primary antibodies. Thus, appropriate controls should be used in each step. Another drawback is that the antibodies used can have a bivalent character and bind both receptors enhancing receptor cross-linking and the PLA reaction can give unspecific nuclear staining. The analysis shows that molecular proximity is necessary for the generation of the PLA signal eg, from A2A-D2 heteroreceptor complexes in striatum (Trifilieff et al, 2011; Borroto-Escuela et al, 2013). The findings indicate that PLA can be used to demonstrate GPCR heteroreceptor complexes ex vivo in brain tissue (Borroto-Escuela et al, 2013; Trifilieff et al, 2011).

Overall, besides the described weaknesses and drawbacks of the fluorescence-based assays, the strengths of these methodologies rely on their usefulness in the discovery and characterization of new GPCR-containing multimeric complexes in living cells and eventually in native tissue (Ferre et al, 2009; Kenakin et al, 2010; Pin et al, 2007). BRET has provided especially strong support for the existence of receptor heteromers in artificial cell systems (Marullo and Bouvier, 2007). It is therefore predicted that BRET will evolve into powerful biotechnological tools in several research areas, such as drug discovery, involving, eg, multiplexing of multicolor BRET (Breton et al, 2010). Another new approach is to measure BRET between a receptor heteromer and a subunit of the heterotrimeric G protein (Urizar et al, 2011). A complemented luminescence is obtained through the receptor-receptor interaction and communication can be measured between a defined heteromer and the G protein without interference from receptor homomers or cross-talk.

\section{GPCRS AND THEIR RECEPTOR-RECEPTOR AND RECEPTOR-PROTEIN INTERACTIONS}

Over the last 15 years large numbers of GPCR heteroreceptor complexes have been discovered characterized by allosteric receptor-receptor interactions, which indicates that such structures represent a general mechanism for molecular integration in the receptor field of high relevance for drug development (Agnati et al, 2003; Albizu et al, 2010; Ciruela et al, 2012; Ciruela et al, 2010; Fuxe et al, 2007b; Fuxe et al, 2009; George and O'Dowd, 2007; Lee et al, 2003; Milligan and White, 2001; Vilardaga et al, 2010). In contrast with the class $\mathrm{C}$ receptors, which exist as stable dimers (Gurevich and Gurevich, 2008a), the class A receptors appear to exist in a monomer-dimer equilibrium, which may vary at different stages of their life cycle (Gurevich and Gurevich, 2008b; Lambert, 2010). This may help explain opposing views on the role of GPCR monomers versus dimers (Chabre and le Maire, 2005; Fotiadis et al, 2006). The class A GPCR dimers are often transient as seen from their half-lives determined from the rate of association and dissociation (Gurevich and Gurevich, 2008b; Lambert, 2010). In the case of the neurotensin NTS1 receptor dimer, we observe a half life of $340 \mathrm{~s}$ at a $\mathrm{Kd}$ value of $20 \mathrm{nM}$ for self-association (White et al, 2007). Furthermore, using total internal reflection fluorescence imaging of single molecules evidence has been found that M1 muscarinic acetylcholine receptors have an estimated half-life of $0.5 \mathrm{~s}$ (Hern et al, 2010). It has been proposed that transient kissand-run heteroreceptor complexes can be of relevance for some forms of ultra-short and short memory (less than $500 \mathrm{~ms}$ ) (Agnati et al, 2010). One possible mechanism for encoding such memories may be the storage of information through on-going allosteric receptor-receptor interactions in higher-order heteroreceptor complexes like tetrameric complexes with a circular organization. In these receptor complexes the allosteric receptor-receptor interactions may result in reverberating receptor activity, which disappears when the transient tetrameric receptor complex falls apart into, eg, two heterodimers.

As to the possible existence of higher-order heteroreceptor complexes in the brain, functional A2AR-D2R-mGluR5 heteroreceptor complexes in the GABAergic striato-pallidal neurons have often been considered based on the high and selective co-expression of mGlu5R, D2R and A2AR in these particular nerve cells, on the existence of A2AR-D2R heteroreceptor complexes (Figure 2) (Canals et al, 2003) and A2AR-D2R-mGlu5R heteroreceptor complexes (Cabello et al, 2009) in living cells and on the existence of strong multiple interactions between the three receptors in striatum (Fuxe et al, 2008a; Popoli et al, 2001).

In cells nearly all functions are mediated by orchestrated multiprotein complexes. Interestingly, apart from interacting with and activating G proteins, GPCRs also bind a plethora of GPCR-interacting proteins (GIPs) (Figure 3). GIPs, either located intracellularly or associated to cell membranes, contain specific GPCR-interacting domains, which sustain, under some cellular conditions, the formation of functional multiprotein complexes necessary for both $G$ protein-dependent and -independent signaling. On the other hand, some GIPs may just act as scaffold proteins which anchor GPCRs to specific plasma membrane domains and thus contribute to the targeting and subcellular distribution of GPCRs. Overall, by impinging on the GPCR trafficking, localization and/or pharmacological properties, GIPs have a prominent role in GPCR biology as they finetune the receptor functioning (Ritter and Hall, 2009). 


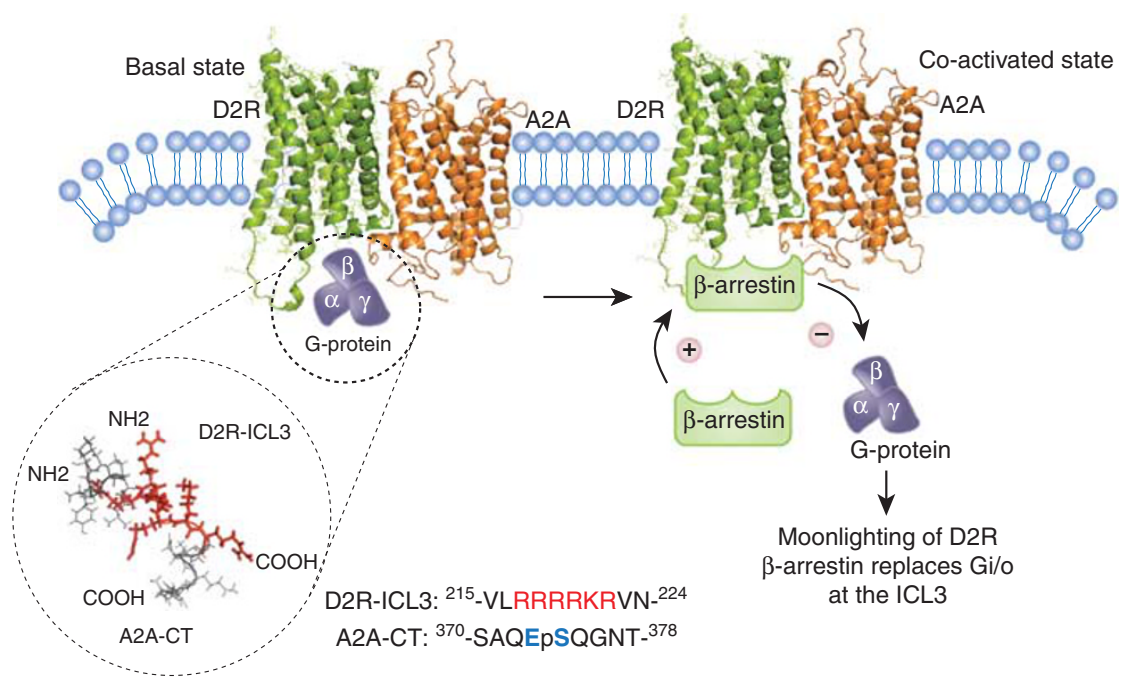

Figure 2. Illustration of receptor protomers in heteroreceptor complexes as moonlighting proteins. The A2A-D2 heteroreceptor complex example. The D2 protomer can moonlight under the influence of the allosteric antagonistic A2A-D2 receptor-receptor interaction (see broad arrow in right receptor complex from A2AR to D2R). It may especially involve the intracytoplasmatic part of the receptor interface with the positively charged arginine rich epitope in D2R-ICL3 (215-VLRRRRKRVN-224) interacting with the negatively charged phosphorylated serine epitope in the A2AR-CT (370SAQEpSQGNT) seen in the left part. The A2A agonist activated receptor-receptor interaction is proposed to moonlight the D2 protomer through a conformational change in the ICL3 strand which switches the ICL3 from binding Gi/o to binding beta-arrestin (right part). Thus, Gi/O signaling of the D2R protomer is reduced and signaling over beta-arrestin dominates associated also with internalization of the receptor complex. A change of function takes place. ICL3, intracellular loop 3; CT, C terminal part.

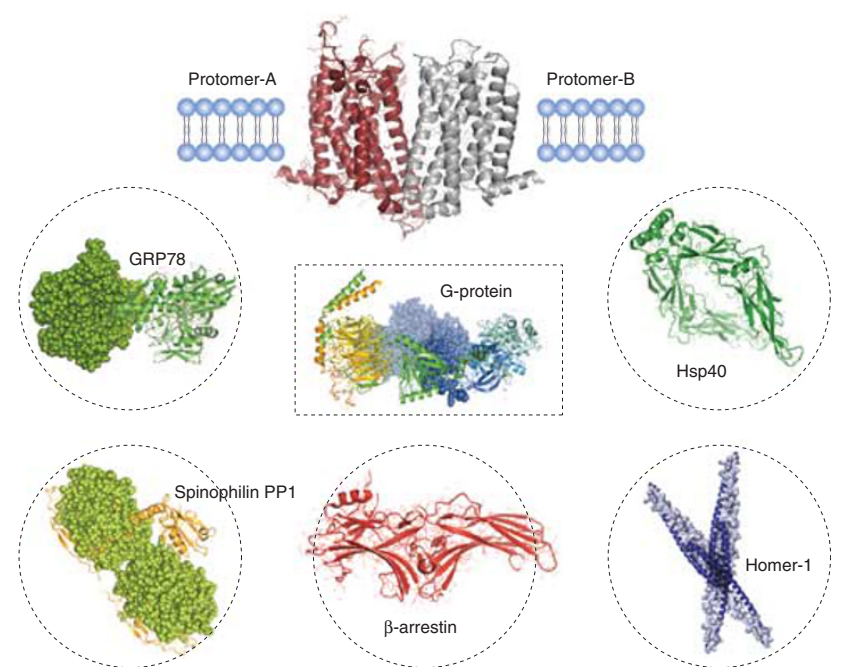

Figure 3. GPCR interacting proteins linked to GPCR heteromers. Apart from interacting with and activating $G$ proteins, GPCR protomers also bind a plethora of GPCR interacting proteins (GIPs). GIPs, either located intracellularly or associated to cell membranes, contain specific GPCR interacting domains, which sustain, under some cellular conditions, the formation of functional multiprotein complexes necessary for both $G$ protein-dependent and -independent signaling. On the other hand, some GIPs may only act as scaffolding proteins, which anchor GPCRs to specific plasma membrane domains (eg, lipid rafts, cell junctions, etc). In this way, they can contribute to the targeting and subcellular distribution of GPCRs. Hsp, heat shock protein; PP1, protein phosphatase 1; GRP, $78 \mathrm{kDa}$ glucose-regulated protein.

\section{RECEPTOR INTERFACE}

Prediction of receptor interfaces may be made with intrinsic disorder analysis showing flexible and malleable regions (Agnati et al, 2008; Guidolin et al, 2010). Potential interfaces in the trans-membrane helices can be estimated using the G-protein-coupled receptor interaction partners method (Guidolin et al, 2010). Extracellular, intracellular, and transmembrane domains of 14 GPCRs have been considered and the propensity of each of these domains for a structured or unstructured conformation has been evaluated through ad hoc computer programs. The N- and C-terminals, as well as intracellular loop 3, have been shown to have a high propensity towards an unstructured conformation. Thus, they are potentially very plastic domains, which interact particularly with other protein domains. The disorder located especially in the intracellular loop 3 (ICL3) and in the C-terminus domain is strongly linked to receptorreceptor interactions.

As an example, we will show that three-dimensional molecular models of the seven TM regions of A2AR and D2LR can be built based on its crystal structure (PDB code 3EML, (Jaakola et al, 2008)) and the crystal structure of rhodopsin (PDB codes 2Z73, (Li et al, 2004)), respectively, as structural templates, by means of the homology modeling program Accelrys Discovery Studio 2.5 (San Diego, CA, USA). Dimerization of GPCR can result from either covalent (disulfide crosslink) or non-covalent unions (electrostatic and hydrophobic unions) between the receptor protomers. Helix-helix interactions are seen from a lateral view. Representation of the D2LR (TM-IV)-A2AR (TM-V) interaction in the A2AR-D2LR heterodimer is shown in Figure 4 (Borroto-Escuela et al, 2011a; Borroto-Escuela et al, 2010d).

In the intracellular part of the receptor interface, a high energy strength double arginine-phosphate electrostatic interaction was found in the A2A-D2 heteromer by Ciruela et al (2004) and Woods et al (2008). It possesses a 


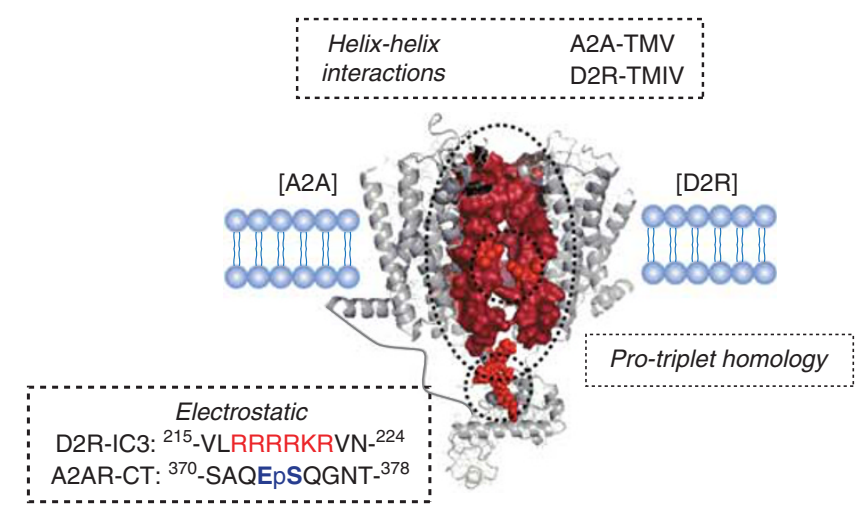

Figure 4. GPCR heteromer receptor interface ilustrated in the A2ARD2R heteromers. (Helix-helix interaction). Representations are shown from a lateral view of the D2R (TM-IVN)-A2AR(TM-IVN) model of the A2AR-D2R heterodimer. (Electrostatic interactions) Illustration of positively charged arginine-rich epitope 215VLRRRRKRVN224 in the $\mathrm{N}$-terminal part of the third intracellular loop of D2R electrostatically interacting with the negatively charged C-terminal epitopes of the A2AR (370-SAQEpSQGNT-378,388-HELKGVCPEPPGLDDPLAQDGAGVS-

412). (Pro-triplet homology interactions) In silico analysis and sequence alignment of $\mathrm{A} 2 \mathrm{AR}$ and $\mathrm{D} 2 \mathrm{R}$ receptor homologies containing the triplet homologies AAR, AQE, VLS, and VYI (in red) in the receptor interface. The triplet homology $\mathrm{VYI}$ is located in the N-terminal of A2AR and in the fifth transmembrane $\alpha$-helix (TM-V) of D2R, the triplet homology VLS is located in the TM-IV of both A2AR and D2R, the triplet homology AAR is located in the third intracellular loop (IL3, between TM-V and TM-VI) of both A2AR and D2R and the triplet homology AQE is located in the IL3 of $\mathrm{D} 2 \mathrm{R}$ and in the $\mathrm{C}$-tail of A2AR. Note that the triplet AQE is adjacent to S374, which seems to have a key role in the A2AR-D2R receptor interfaces. Also note that the triplet $\mathrm{VYI}$ cannot have a role as the homology is located in the N-terminal part of the A2AR and the fifth TM region of the $\mathrm{D} 2 \mathrm{R}$.

covalent-like stability as has been demonstrated with mass spectrometry in combination with collision-induced dissociation experiments and confirmed by pull-down techniques (Ciruela et al, 2004; Woods et al, 2008). A mass spectrum is produced from a mixture of A2AR and D2R epitopes. The mixture of the negatively charged A2A serinephosphate containing motif from the C-terminal A2A and the positively charged D2 VLRRRRKRVN arginine rich motif from the IC loop 3 results in the formation of a noncovalent complex (Figure 4). These electrostatic interactions likely represent important hot spots also in the receptor interface (IC loop 3 of D3/D4-C-terminal of A2A) of the putative A2AR-D3R and A2AR-D4R heteromers (Fuxe et al, 2005; Torvinen et al, 2005). These electrostatic bonds in the intracellular part of the receptor interface may be dynamically regulated by kinases and phosphatases which increase and reduce the stability of the heterodimer formed.

The importance of these electrostatic interactions between A2AR and D2R has now been validated by a point mutation of serine 374 to alanine in the A2AR C-terminal tail which reduces the A2AR ability to interact with D2R. This is seen from the reduction of BRET signals and thus of heteromerization, which is enhanced in combination with mutation of the two aspartates (Borroto-Escuela et al, 2010b; Borroto-Escuela et al, 2010d). BRET1 studies have been performed on A2AR and D2LR heteromerization in HEK293T cells. BRET1 saturation curves have been obtained for the D2LR-A2AR heteroreceptor complex and compared with D2LR-A2AR mutant heteroreceptor complex. The comparison shows markedly reduced BRETmax values after serine 374 point mutation, especially in combination with the mutation of the two aspartates in the A2AR C-terminal. Moreover, this point mutation abolishes the A2AR-mediated inhibition of both the D2R high-affinity agonist binding and signaling as studied for example in a forskolin-induced cAMP-response element (CRE)-luciferase reporter gene assay. The forskolin-induced increase of luciferase activity by a direct activation of AC is significantly reduced by quinpirole, an action which is fully counteracted by the A2A agonist and by the D2R like antagonist raclopride. However, after the single point mutation of serine 374 in the A2AR, it is no longer possible for the A2A agonist $(50 \mathrm{nM})$ to counteract the quinpiroleinduced reduction of luciferase activity, while raclopride is still able to counteract it. These results validate a key role of serine 374 in the A2AR-D2R interface in making the allosteric modulation of the $\mathrm{D} 2 \mathrm{R}$ possible. Serine 374 is also evolutionary conserved.

Electrostatic interactions have also been shown to be involved in the cytoplasmic receptor interface of the D1D2R heteromer (O'Dowd et al, 2011). The two adjacent positively charged arginins in D2R IC loop3 are necessary for the D1-D2R heteroreceptor complex formation as were two adjacent negatively charged glutamate residues in the $\mathrm{C}$-terminal tail of the D1. These results validate the impact of electrostatic interactions in the intracellular part of the receptor interface between IC3 and the C-terminal for the formation of GPCR heteroreceptor complexes.

\section{THE ROLE OF THE TRIPLET PUZZLE IN THE RECEPTOR INTERFACE}

Based on a mathematical approach, Tarakanov and Fuxe $(2010,2011 \mathrm{a})$ deduced a set of triplet homologies ('triplet puzzle') that may be responsible for protein-protein interactions, including receptor heteromers, and human immunodeficiency virus (HIV) entry. For example, the triplet of amino-acid residues LLG (Leu-Leu-Gly) appears as a homology in six receptor heteromers (ie, in both receptors, see Table 1): 5 -hydroxytryptamine $1 \mathrm{~A}$ receptor (5HT1AR)-fibroblast growth factor receptor 1 (FGFR1), 5HT1AR-galanin receptor 1 (GalR1), FGFR1-platelet-derived growth factor receptor, alpha polypeptide (PDGFRA), 5-HT2A receptor (5HT2AR)-metabotropic glutamate receptor 2 (mGluR2), adrenergic receptor, alpha1B (ADRA1BR)-adrenergic receptor, alpha 1D (ADRA1DR), and cannabinoid receptor type $1(\mathrm{CB} 1 \mathrm{R})$-cannabinoid receptor type 2 (CB2R), but does not appear as a homology in any known non-heteromers (GABAB2 receptor subunit 
TABLE 1 Example of Triplet Homologies in the Protomers of Human Receptor Heteromers and Marine Sponges

\begin{tabular}{|c|c|c|c|c|c|c|}
\hline Receptor heteromer & Species & Reference & Function & LLG & KTV & TVS \\
\hline 5HTIA-FGFRI & Human & (Borroto-Escuela et al, 2012a) & MAPK signal and neuronal plasticity & + & + & + \\
\hline DI-NMDA & Human & (Lee et al, 2002) & Modulation of NMDA signaling & - & - & + \\
\hline FGFRI-PDGFRA & Human & (Faraone et al, 2006) & Receptor binding, signal and the control of endothelial cell function & + & \# & - \\
\hline 5HT2A-mGluR2 & Human & (Gonzalez-Maeso et al, 2008) & Activation of mGluR2 inhibits hallucinogen-specific signaling of $5 \mathrm{HT} 2 \mathrm{~A}$ & \# & - & - \\
\hline TLRI-TLR2 & Human & (Jin et $a l, 2007)$ & $\begin{array}{l}\text { Expression of pro- and anti-inflammatory cytokine genes and role in innate } \\
\text { immune response }\end{array}$ & - & + & - \\
\hline ITGA-ITGB & Sponge & (Pancer et al, 1997) & Cell-to-cell contacts and cell-to-extracellular matrix interactions & - & - & \# \\
\hline
\end{tabular}

Abbreviations: ADRAID, alpha-ID adrenergic receptor; CBI, cannabinoid receptor I; CB2, cannabinoid receptor 2; DI, dopamine DI receptor; FGFRI, fibroblast growth factor receptor I; GaIRI, galanin receptor type I; 5-HTIA, 5-hydroxytryptamine receptor IA; 5HT2A: 5-hydroxytryptamine receptor 2A; ITGA, metazoan adhesion receptor subunit integrin- $\alpha$; ITGB, metazoan adhesion receptor subunit integrin- $\beta$; mGluR2, metabotropic glutamate receptor; 2PDGFRA, platelet-derived growth factor receptor alpha; TLRI, toll-like receptor I; TLR2, Toll-like receptor 2.

Amino acid description one/three letter code: LLG (Leu-Leu-Gly), KTV (Lys-Thr-Val), and TVS (Thr-Val-Ser)

$(+$, yes in both receptors, \#, may mediate their interaction, and - , not in any receptor).

The acronyms are listed according to the UniProtKG Accession number (in bold): 5-HTIA (P08908); FGFRI (PI I362); DI (P2 I 728); GalRI (P472I I);

PDGFRA (P I 6234); 5HT2A (P28223); mGluR2 (Q I 44I6); Alpha-ID adrenergic receptor (P25 I 00); ADRAID (P25 I 00); CBI (P2 I 554); CB2 (P34972);

TLRI (Q 15399); TLR2 (O60603); ITGA (CAA65943); ITGB (CAA7707I).

(GABAB2R)-A2AR, A2A-dopamine receptor 1(D1R), adenosine receptor $1(\mathrm{~A} 1 \mathrm{R})-\mathrm{D} 2 \mathrm{R}$, neurotensin receptor 1(NTS1)-D1R, thyrotropin receptor (TSHR)-D2R, and cluster of differentiation 4 glycoprotein (CD4)-D2R; (Tarakanov and Fuxe, 2010). According to recent biochemical studies (Borroto-Escuela et al, 2012a; RomeroFernandez et al, 2011), such triplets exist in the interacting domains forming the receptor interface. Furthermore, a 'guide-and-clasp' manner of receptor-receptor interactions has been proposed where the 'adhesive guides' may be the triplet homologies (Tarakanov and Fuxe, 2010). These interactions probably represent a general molecular mechanism for receptor-receptor interactions (Fuxe et al, 2012). This hypothesis is supported by the demonstration that the SVR triplet homology in IC loop3 of the mu-delta opioid receptor heteroreceptor complex (MOR-DOR) is crucial for the formation of this complex (O'Dowd et al, 2011). Based on this theory, for the first time it was indicated that several triplet homologies of the heteroreceptor complex 5HT1AR-FGFR1 as well as of other receptor heteromers of the human brain may be the same as in cell-adhesion receptors (built as heterodimers) of marine sponges (Tarakanov et al, 2012a, b), known to be highly conserved from the lowest metazoa to vertebrates (Buljan and Bateman, 2009; Gamulin et al, 1994; Pancer et al, 1997).

Materials and methods related to recent biochemical studies of the interacting domains of the receptor-receptor interface have been described thoroughly in our previous papers (for example, see Borroto-Escuela et al (2012a)). In brief, with in situ proximity ligation assay (PLA) and supported by coimmunoprecipitation and colocation of the 5HT1AR and FGFR1 immunoreactivities evidence for the existence of 5HT1AR-FGFR1 heteroreceptor complexes in the hippocampus and dorsal and median raphe nuclei of the rat has been obtained. Taken together, the $5 \mathrm{HT} 1 \mathrm{~A}$ receptors comprise part of a 5HT1AR-FGFR1 heteroreceptor complex. The triplet homologies and the existence of a basic set of triplets in the two participating protomers that may be responsible for their homo- or heterodimerization were computed using a modified version of our original software (Tarakanov and Fuxe, 2010).

The triplet homologies LLG (Leu-Leu-Gly), KTV (LysThr-Val), and TVS (Thr-Val-Ser) exist in several categories of receptors in the human brain (Table 1) and also in marine sponges. Particularly, the triplet TVS (Thr-Val-Ser) exists in both integrin- $\alpha$ and integrin- $\beta$ subunits of marine sponges. The triplet LLG (Leu-Leu-Gly) is only found in the integrin- $\beta$ subunit, whereas the triplet KTV (Lys-Thr-Val) does not appear in any subunit (Table 1). The location of the KTV and TVS triplets in the different categories of receptor heteromers and proteins is displayed in Figure 5, whereas the location of the triplet LLG in these receptors and proteins (Table 1) is present and discussed in the paper by Tarakanov and colleagues (Tarakanov et al, 2012a). Among the GPCRs, such triplets can be located in several types of domains including their interface mediating the receptor-receptor interactions (see Figure 5 and the references in Table 1).

For example, the LLG triplet homology has been identified in six receptor heteromers: 5HT1AR-FGFR1, 5HT1AR-GalR1, FGFR1-PDGFRA, 5HT2AR-mGluR2, ADRA1BR-ADRA1DR, and CB1R-CB2R (Table 1). These LLG triplets are mainly located in the transmembrane interface of these heterodimers where hydrophobic leucinerich motif residues enable the formation of a hydrophobic area at the helix-helix interface, facilitating receptor-receptor interactions (Tarakanov et al, 2012c). They may mediate 


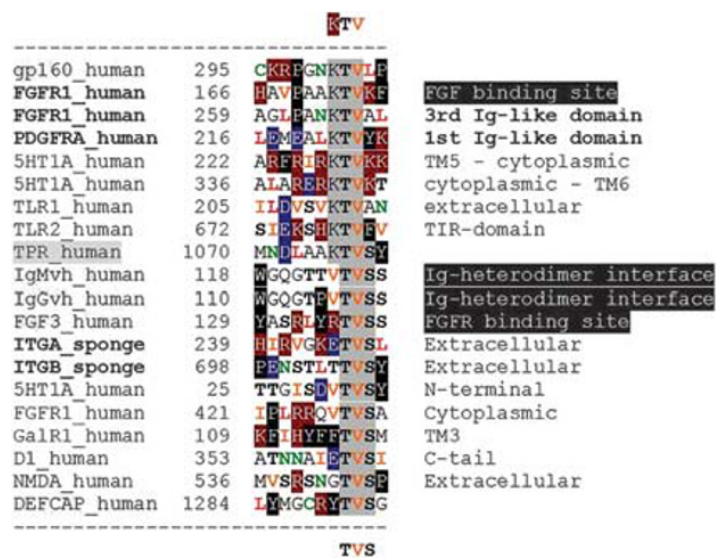

Figure 5. Examples of triplet homologies (dark shaded) KTV (Lys-ThrVal) and TVS (Thr-Val-Ser) in marine sponges and different types of receptors and proteins: light shaded are six proteins (envelope HIV glycoprotein (gp160), tetratricopeptide repeat (TPR; scaffolds to mediate protein-protein interactions), IgG heavy chain variable region (IgGvh), IgM heavy chain variable region (IgMvh), FGF3, and death effector filamentforming CED4-like apoptosis protein (DEFCAP); bold text marks two receptor heteromers (human FGFR1-PDGFRA and marine sponge ITGAITGB), which may possess the corresponding triplet homologies KTV and TVS in their interfaces; TM is the transmembrane $\alpha$-helix of GPCR. Three following amino acids are shown in white letters on the black background as the basic elements of protein binding: W (Trp), F (Phe), and P (Pro). The following amino-acid residues are marked by a color code as the basic elements of leucine-rich motifs. Red bold L is leucine (Leu). Orange bold I and $V$ are isoleucine (lle) and valine (Val) that may also occupy a position of Leu in leucine-rich motifs. Green N and C are asparagine (Asn) and cysteine (Cys). Black bold S and T are serine (Ser) and threonine (Thr) where agonist-regulated phosphorylation may occur. White letters are charged amino acids: negatively charged (dark blue background) E (Glu) and $\mathrm{D}$ (Asp) or positively charged (dark red background) R (Arg), K (Lys), and $\mathrm{H}$ (His).

interactions of 5HT1AR-GalR1 (via their TM1-TM4 interface), 5HT2AR-mGluR2 (TM2-TM2), and ADRA1BRADRA1DR (TM4-TM4). In line with this view, leucine-rich repeats are known to contribute to protein-protein interactions (Kobe and Kajava, 2001) and the leucine zipper functions as a structural motif in proteins where the hydrophobic leucine residues helps bonding of adjacent transmembrane helices (Landschulz et al, 1988). However, the same triplets will not interact in FGFR1-PDGFRA (as the triplet LLG is cytosolic in FGFR1 and extracellular in PDGFRA) and 5HT1AR-FGFR1 (transmembrane in 5HT1A and cytosolic in FGFR1).

In contrast, the triplet LLG is not present in the D1-NMDA receptor heteromer, toll-like receptor heteromers, and integrin heteromer of marine sponges (see Table 1). Although the triplet KTV is found in 5HT1AR (in the third intracellular loop between TM5 and TM6, see Figure 5), FGFR1 (in its ligand binding site and the third Ig-like domain), PDGFRA (in the first Ig-like domain), Toll-like receptor 1 (TLR1) (in the extracellular domain), and Tolllike receptor 2 (TLR2) (in the intracellular signaling domain TIR), an interaction may only be mediated in FGFR1PDGFRA heteromers (by their Ig-like domains, see Figure 5 and Table 1). In addition, the triplet TVS may mediate an interaction between the subunits of the integrin receptor heteromer (integrin subunit, alpha (ITGA)- integrin subunit, beta (ITGB) of marine sponges (by their extracellular domains). These observations strengthen our theory that these triplet homologies ('triplet puzzle') participate in recognizing the other receptor protomer of the heteromer via postulated 'guide-and-clasp' interactions in the receptor interface (Fuxe et al, 2012; Tarakanov and Fuxe, 2010, 2011a; Tarakanov et al, 2012a). In fact, indications exist for their location in the receptor interface (Borroto-Escuela et al, 2012a; Romero-Fernandez et al, 2011), which can involve different categories of receptor heteromers.

It should also be noted that the set of integrin triplets of marine sponges does not exclude the presence of other sets of triplets, which seem to be typical for several kinds of receptor heteromers, including their possible origin from protein-protein interactions (Tarakanov et al, 2011b, 2012a). For example, the triplets SSS (Ser-Ser-Ser), SGS (Ser-Gly-Ser), and GGG (Gly-Gly-Gly) found in variable chains of IgG and IgM participating in antigen recognition also exist as triplet homologies in two GABAB1-containing heteromers: GABAB1-mGluR1 and GABAB1-C-X-C chemokine receptor type 4 (CXCR4) (Tarakanov et al, 2012c). Furthermore, substitution of any of the three GGG residues in the C-terminal tail of the delta opioid receptor has been found to disrupt the mu-delta opioid receptor heteromer (O'Dowd et al, 2012). Another example is the set of triplet homologies LLE (Leu-Leu-Glu), LEE (Leu-Glu-Glu), and NNL (Asn-Asn-Leu), which looks typical for a set of three receptor heteromers: GABAB1-GABAB2 (GABA B receptor), TLR1-TLR2, and TLR2-TLR6 (Tarakanov et al, 2012c). As for marine sponges, the triplet RAA (Arg-Ala-Ala) may mediate the heteromerization of the serotonin and the fibroblast growth factor receptors subtypes $5 \mathrm{HT} 1 \mathrm{AR}$ and FGFR1 (Tarakanov et al, 2012b), whereas the triplets AVI (Ala-Val-Ile) and DLL (Asp-Leu-Leu) may help mediate the heteromerization of the dopamine receptors D1 and D2 (Tarakanov et al, 2012b). Thus, we can postulate that such sets of triplet homologies may determine the specificity of receptor-receptor interactions.

It appears that such triplets may have a role in neuroinflammation and other disorders (Tarakanov et al, 2011b). Such findings may also give a new molecular basis for the therapeutic actions of antidepressant drugs as their increase of extracellular 5-HT in the brain can activate the receptor heteromer 5HT1A-FGFR1 in the hippocampus restoring FGFR1 signaling and neuronal plasticity, which may potentially reduce the atrophy of the hippocampus found in depression (Borroto-Escuela et al, 2012a; BorrotoEscuela et al, 2011b).

Parts of the triplet puzzle of homologies in receptor heteromers appear to originate from the cell-adhesion receptor triplets of marine sponges, which are phylogenetically very old. Thus, the triplet puzzle may be part of a general mechanism for protein-protein interaction. For example, these triplets may 'guide-and-clasp' direct 
protein-protein interactions by the involvement of leucinrich motifs as well as a flexibility of the protein skeleton provided by LLG (Leu-Leu-Gly), phosphorylation of serine in TVS (Thr-Val-Ser) and electrostatic interactions of lysine in KTV (Lys-Thr-Val).

\section{PROTOMERS IN HETERORECEPTOR COMPLEXES CAN ACT AS MOONLIGHTING PROTEINS VIA INTERMOLECULAR RECEPTOR-RECEPTOR INTERACTIONS}

As mentioned in the discussion on moonlighting proteins, indications exist that changes in the allosteric receptorreceptor interactions among receptor protomers through the formation of different types of receptor heteromers can alter the function of the individual receptor protomer. Moonlighting can also develop in the receptor protomer via actions of receptor agonists and allosteric modulators. In this way, through conformational changes in these heteroreceptor complexes, moonlighting may develop in a single GPCR protomer by, for example, switching its coupling to other types of $\mathrm{G}$ proteins, to beta-arrestins, to other types of GPCR-interacting proteins, to receptor tyrosine kinases (RTKs) and to ion channel receptors and through changes in its orthosteric site altering its transmitter and agonist specificity (Bockaert et al, 2003; Borroto-Escuela et al, 2011a; Fuxe et al, 2007b; Hasbi et al, 2011).

A single GPCR protomer may undergo changes in cotrafficking with increased internalization through changes in allosteric receptor-receptor interactions due to its participating in altered heteroreceptor complex. The internalized receptor may then become linked to cytosolic proteins leading to an altered conformation and transport to the nuclei. The receptor may then moonlight as a transcription factor. As possible transcription factors, the GPCRs could directly modulate gene expression of high relevance for information handling, trophism, and neurodegeneration. A pathological change in the moonlighting properties of a receptor protomer may have major consequences for its function, especially of receptor protomers having a multitasking role with multiple interactions with other receptors and proteins, so-called hub receptors (Tarakanov et al, 2012b). A moonlighting dysfunction in a hub receptor protomer of key molecular networks may substantially contribute to the development of neurological and mental disorders.

One early example of moon-lighting is the GABAB receptor, which is a heterodimer formed from GABABR1 and GABABR2 subtypes that alone may only function as chaperone proteins and receptor interacting proteins. By their heteromerization mainly via their C-termini (coiledcoil interaction) they become the GABAB receptor, which bind GABA via GABABR1 and signal to the $G$ protein via GABABR2 (Marshall et al, 1999). Thus, a novel function of acting as a receptor has developed through the proteinprotein interaction.
The D1R-D2R heteroreceptor complex, discovered by the (George and O'Dowd (2007) and Rashid et al (2007b)), is a beautiful example of moonlighting of receptor function. The D1R-D2R heteroreceptor complex demonstrates how the formation of such a complex can switch the $G$ protein coupling of participating protomers (D1R: Gs; D2R: Gi) to other $\mathrm{G}$ proteins $(\mathrm{Gq})$ (Rashid et al, 2007a). Thus, upon coactivation of D1R and D2R in this heteromer, a selective $\mathrm{Gq} / 11$ activation occurs, which produces increases in phospholipase C (PLC) activity and a rapid rise in intracellular calcium levels without influencing adenylate cyclase activity regulated by Gs and Gi proteins. Thus, the PLC activation leads to intracellular calcium release and increased levels of calcium/calmodulin dependent protein kinase II alpha (CaMKII), which contributes to synaptic plasticity and behavioral sensitization to drug treatment (Hasbi et al, 2011; Rashid et al, 2007b). These results illustrate how allosteric receptor-receptor interactions between the D1R and D2R protomer can produce moonlighting of their functions by switching their coupling to $\mathrm{Gq}$ upon their coactivation. The dysfunction of the D1R-D2R heteroreceptor complex may contribute to neuropsychiatric diseases (Hasbi et al, 2011).

This heteroreceptor complex via the allosteric receptorreceptor interaction has also been shown to moonlight D1 and D2 protomer recognition giving them a unique pharmacology (Rashid et al, 2007a; Rashid et al, 2007b). The D1R agonist SKF83959 has been found to be a selective agonist for this receptor heteromer by being a full agonist at the D1R protomer and a partial agonist at the D2R protomer existing in a pertussis toxin-insensitive state leading to rapid activation of Gq/11 and PLC. On the other hand, the D1R-like agonist SKF83959 does not activate adenylyl cyclase (AC)-linked $\mathrm{D} 1 \mathrm{R}$ and $\mathrm{D} 2 \mathrm{R}$ and may, therefore, be a unique agonist for the D1R-D2R heteroreceptor complex. Thus, this work represents an interesting example of how moonlighting changes in the receptorbinding domains of the two protomers in the D1R-D2R heteroreceptor complex generate new recognition specificity and new drugs for neuropsychopharmacology. In fact, an increased proportion of the D1R-D2R heteroreceptor complex is in a high-affinity state in schizophrenia and after chronic amphetamine treatment.

Moonlighting in A2AR-D2R heteroreceptor complexes can also be seen from the A2AR agonist modulation of the D2R agonist induced beta-Arrestin2 recruitment (Borroto-Escuela et al, 2011a). The results indicate that the antagonistic allosteric receptor-receptor interaction in A2AR-D2R heteroreceptor complex favors beta-arrestin2 recruitment to the $\mathrm{D} 2 \mathrm{R}$ protomer with subsequent cointernalization associated with a reduced time onset of Akt phosphorylation followed by a rapid dephosphorylation. Thus, beta-arrestin 2 action becomes more rapid and short-lived and, in this way, mimics $\mathrm{G}$ protein-mediated signaling (Borroto-Escuela et al, 2011a). The moonlighting of the $\mathrm{D} 2 \mathrm{R}$ protomer that takes place via the antagonistic allosteric A2AR-D2R interaction results in 
a rapid switch from D2-Gi coupling towards beta-arrestin2-mediated D2R signaling linked to the formation of a possible A2AR-D2R-beta-arrestin2 complex (Figure1) (Borroto-Escuela et al, 2011a).

Another moonlighting phenomenon in the A2AR-D2R heteroreceptor complex is that the positively charged D2R $\mathrm{N}$-Terminal ICL3 epitope (VLRRRRKRVN) may switch from binding to the negatively charged A2AR epitope (SAQEPSQGNT), located in the medium segment of the C-terminus of the A2AR (Ciruela et al, 2004), to several negative epitopes of calmodulin (Woods et al, 2008), which alters the function of the $\mathrm{D} 2 \mathrm{R}$ protomer through the involvement of calmodulin mediated signaling. This moonlighting phenomenon is modulated by calcium ions since they disrupt the binding of calmodulin to the D2R but not the A2AR (Woods et al, 2008), which favors the binding of the D2R N-terminal ICL3 epitope to the A2AR epitope or to epitopes of Gi/o. It is likely that in the absence of A2AR agonist activation with reduced antagonistic allosteric A2AR-D2R interactions, the conformational state in the ICL3 of D2R may favor its link to Gi/o. This may involve inter alia electrostatic interaction between triplets AAR (in D2R ICL3) and AAE (Gi/alpha1) (and/or their symmetric variants), which contributes to guide-and-clasp D2R-Gi/o interactions with maintenance of its major physiological role as activator of $\mathrm{Gi} / \mathrm{o}$ signaling.

Changes in A1R recognition have been discovered by Nakata et al (2005) in A1R-P2Y1 heteroreceptor complex which gives evidence for moonlighting in the A1 receptor protomer of this heteromer. This heteromerization results in a conformational change in the A1R binding pocket, which leads to the appearance of an A1R receptor with P2Y1-like agonist pharmacology. In fact, a P2Y1 agonist binds to the A1R and produces an inhibition of $\mathrm{AC}$, which is blocked by an A1R antagonist. Therefore, this A1Rmediated ATP response can be one of the mechanisms that might account for the ATP-induced inhibition of transmitter release, as ATP is inter alia coreleased with glutamate from nerve terminal networks. The moonlighting achieved via the allosteric A1R-P2Y1 receptor-receptor interaction is the formation of an A1R protomer with a P2Y1-like pharmacology leading to ATP recognition.

It seems likely that moonlighting may develop in the intracellular loops and C terminal of the GPCRs, especially in the long ICL3, as a result of dynamic allosteric interactions between different types of $\mathrm{G}$ proteins and other receptor interacting proteins in these domains of the receptor. Because of these dynamic conformational changes, the same amino-acid strand in these domains may in one state bind to a certain $G$ protein and in a different state to another signaling protein, which may be a result of changes in guide-clasp interactions of this motif in relation to the interaction domains of these two signaling proteins. In this way, the receptor may change its signaling function and dynamic multitasking actions could develop. In the case with receptor-interacting proteins, the moonlighting will mainly operate by having intracellular signals change the function of the GPCR as a result of intracellular demands. In the case of moonlighting in heteroreceptor complexes, it is instead the result of a demand from the environment to integrate two or multiple signals into novel functions via changes in single amino-acid strands of several receptor domains, which takes place through allosteric receptorreceptor interactions in the extracellular, transmembrane, and intracellular domains. The integration of signals in higher-order heteroreceptor complexes may result in a more complex moonlighting phenomenon.

The field of moonlighting proteins continues to expand in this case into the field of receptor proteins, especially in relation to their formation of GPCR-GPCR and GPCR-RTK heteroreceptor complexes. The allosteric receptor-receptor interactions lead to changes in the guide-clasp interactions of key receptor motives involved in agonist/antagonist binding and binding of signaling proteins so that moonlighting develops. Therefore, another type of recognition and pharmacology can be found and another signaling protein spectrum is selected (biased agonism). The moonlighting in the GPCR-RTK heteroreceptor complexes may have special relevance for counteracting neurodegenerative processes and depression induced atrophy of neurons in view of the impact of RTK signaling on nerve cell survival and differentiation. Moonlighting in GPCR homoreceptor complexes may likely also develop due to the binding of multiple GPCRs and signaling proteins including the G proteins to the intracellular domains of the protomers. This alters via allosteric mechanisms the guide-clasp interactions between the strands of amino acids belonging to the protomer motives and the domains of different signaling proteins, which changes the pattern of receptor-protomer signaling.

\section{DRUG DEVELOPMENT BASED ON RECEPTOR-RECEPTOR INTERACTIONS IN GPCR HETERORECEPTOR COMPLEXES}

The field of receptor-receptor interactions in GPCR containing heteroreceptor complexes and protein-protein interactions in general have opened up new targets for drug development (Agnati et al, 2003; Fuxe et al, 1989; George et al, 2002) and several strategies can be exploited to develop new drugs based on targeting the heteroreceptor complexes (Soriano et al, 2009). Bivalent and dimeric ligands were introduced early on and have proven to markedly increase receptor affinity (Halazy et al, 1996; Perez et al, 1998) but, paradoxically, this design was not based on the existence of heteroreceptor complexes (George et $a l, 2002)$. The potential value of this approach is illustrated by the demonstration that opioid-induced tolerance and dependence in mice is modulated by the distance between pharmacophores in a dimeric ligand series (mu-delta agonist-antagonist (MDAN) (Daniels et al, 2005). These dimeric ligands likely target the mu-delta opioid heteroreceptor complexes (George et al, 2000; Gomes et al, 2004) in which the delta opioid receptor antagonist blocks 
the antagonistic delta-mu opioid receptor-receptor interaction. This leads to enhanced mu opioid receptor activity and potentiated morphine analgesia. With MDAN spacer arms of 19 atoms or above morphine-induced dependence and tolerance have been counteracted giving indications that the antagonistic allosteric receptor-receptor interactions in the mu-delta opioid receptor heteroreceptor complex are involved in producing dependence and tolerance to morphine (Daniels et al, 2005).

An increased abundance of mu-delta opioid receptor heteroreceptor complexes has recently been found after chronic morphine administration (Gupta et al, 2010). Chronic, but not acute, morphine treatment causes an increase in the abundance of these heteroreceptor complexes in key areas of the CNS, which are implicated in pain processing. Because of its distinct signaling properties, the mu-delta opioid heteroreceptor complex may, as outlined above, counteract morphine action and be a therapeutic target in the treatment of chronic pain and addiction (Gupta et al, 2010). This work is possible through a subtractive immunization strategy, which generates antibodies that selectively recognize the endogenous mu-delta opioid heteroreceptor complex but do not recognize single mu or delta opioid receptors (Rozenfeld and Devi, 2010). All these data support the view that this heteroreceptor complex is a drug target for treatment of morphine tolerance and dependence, as this complex develops a reduced $G$ protein-coupling with signaling mainly operating via $\beta$ arrestin2 upon chronic morphine treatment. Treatment with delta opioid receptor antagonists in animal models reduces the $\beta$-arrestin2 coupling in the mu-delta opioid heteroreceptor complex and enhances mu opioid-protomer binding, signaling, and morphine-induced antinociception, which may be associated with a disruption of the mu-delta opioid-receptor-heteroreceptor complex.

George and O'Dowd (2007) were the first to demonstrate that agonists selective for a discrete heteroreceptor complex can be developed, in this case the D1-D2 heteroreceptor complex (Lee et al, 2004; Rashid et al, 2007a; Rashid et al, 2007b). Thus, SKF 83959 is a specific D1-D2R heteroreceptor complex agonist at the orthosteric-binding sites. The search continues for specific heteroreceptor complex agonists and antagonists as tools and potential drugs for mental and neurological diseases treatment. Such drugs have the potential to offer therapeutic effects with substantially reduced side-effects.

One major strategy is to target heteroreceptor and other protein complexes to develop a molecule that antagonizes a receptor-receptor interaction and more generally a protein/ protein interaction, which interferes with the complex formation. It is therefore of great importance to identify the molecular structure of at least part of the receptor interface. Transmembrane interface interfering peptides have successfully been introduced to target selected heteroreceptor complexes like, eg, the FGFR1-5HT1A heteroreceptor complex (Borroto-Escuela et al, 2012a) leading to a marked reduction of the receptor-receptor interaction. These transmembrane interfering peptides are also useful for determining if an observed change of a receptor protomer function is caused by an allosteric receptor-receptor interaction or by receptor cross-talk in the intracellular signaling cascades. In addition, with increased understanding of the receptor interface it may be possible to develop drugs, which by targeting the receptor interface enhances the allosteric receptorreceptor interaction and/or increases their formation. This will be beneficial in the case, eg, of the FGFR1-5HT1A heteroreceptor complex, as it may enhance the ability of the 5-HT1AR protomer to increase the activity of the FGFR1 protomer. Neuroplasticity and trophism should in this way be improved. It is also possible that positive and negative allosteric modulators of one protomer can have a major role in modulating the function of the other protomer in the heteroreceptor complex through similar mechanisms.

The receptor interface has become an important target for the development of neurotherapeutic drugs and for understanding the function of heteroreceptor complexes and other protein complexes. Disrupting heteroreceptor and protein complexes in the cytoplasmic part of the receptor interface is possible through the use of Tat-tagged peptide mimics (Li et al, 2011). Tat is an 11-amino acid protein transduction domain of the HIV-1 Tat protein, which allows the peptide that mimics part of the intracellular receptor interface to pass through the plasma membrane of live cells in brain tissue. In this way, it becomes possible to block, eg, the electrostatic interactions in the intracellular receptor interface of heteroreceptor complexes and to understand their role in heteroreceptor complex function. The identification of interacting hot spots of protein-protein interactions in the receptor interface like the electrostatic receptor-receptor interactions is of special interest. They likely represent key targets for novel neurotherapeutics acting as modulators of receptor-receptor interactions in the heteroreceptor complexes and of protein-protein interactions in general in protein complexes.

Based on RET methods alone or in combination with bimolecular fluorescence complementation, evidence shows that three GPCRs can exist in close proximity in living cells compatible with the existence of GPCR higher-order heteroreceptor complexes (see methodological section). It may therefore be speculated that in CNS higher-order heteroreceptor complexes (receptor mosaics; RM) may exist and offer several additional targets for drug development. Novel drugs may be developed to modify the composition of RM, their topography, order of activation as well as allosteric regulators modulating the functional state of the individual receptors in the RM. Drugs may affect, for example, (I) the synthesis and release of heteroreceptor complex building blocks from the endoplasmic reticulum, (II) the insertion of such building blocks into the plasma membrane, (III) the internalization of RMs, (IV) the adapter and scaffolding proteins organizing the RMs, and (V) ligand induced heteroreceptor complex assembly. The potential importance of developing allosteric modulators 
has also been suggested (Milligan and Smith, 2007), as they may, inter alia, substantially affect the allosteric mechanisms within the RM, which leads to changes in its integrative function. Currently, it is relatively unknown how allosteric modulators at one receptor protomer influence the function of the other receptor protomers in a heteroreceptor complex via the allosteric receptor-receptor interactions. Understanding such actions of allosteric receptor antagonists and agonists may likely also offer opportunities for introduction of novel neurotherapeutic drugs.

Another approach in developing peptides that interfere with protein/protein interactions is that of replacing some natural amino acids with non-natural amino acids. This approach has been used to develop short peptides for the SH3 domains. These domains are very important for protein/protein interactions as they are small docking units present in many signal transduction proteins (Pawson et al, 2001; Pawson and Scott, 1997). It has therefore been possible to replace parts of the polyproline helix-recognition sequences with nonnatural, N-substituted glycine residues (Nguyen et al, 1998). These peptide-peptoid hybrids often have higher affinity than that of the natural peptide and improved specificity for SH3 domains (Cochran, 2000). By competing for binding to the SH3 domain, they may stop the signal along the wiring pathways in the cytoplasm such as the RTK-Ras-MAP kinase pathway.

\section{A2A-D2 HETERORECEPTOR COMPLEXES AND THEIR RECEPTOR-RECEPTOR INTERACTIONS IN RELATION TO PARKINSON'S DISEASE AND AS TARGETS FOR NOVEL ANTIPARKINSON DRUGS}

The striatal A2A-D2 heteroreceptor complexes (BorrotoEscuela et al, 2013; Canals et al, 2003; Trifilieff et al, 2011) have been proposed to be an important target for antiparkinsonian drugs based on the existence of antagonistic A2A-D2 receptor-receptor interactions within them (Fuxe et al, 1998). In the striato-pallidal GABAergic neurons, this heteroreceptor complex exists in equilibrium with A2A and D2 homoreceptor complexes (George et al, 2002) on the plasma membrane (Ciruela et al, 2012; Fuxe et al, 2007a; Fuxe et al, 2010; Fuxe et al, 2007c). A2A-D2 heteroreceptor complexes strongly modulate the excitability in the striato-pallidal GABAergic neurons via their ability to counteract the inhibitory D2R signaling to multiple effectors upon agonist activation of the A2AR protomer. The counteraction of the D2R-induced inhibition of the $\mathrm{Ca} 2+$ influx over the L-type voltage-dependent $\mathrm{Ca} 2+$ channels (Cav 3.1 channels) by A2AR activation leads to increased phosphorylation of this calcium channel, which causes an increased opening of the channel and to an upstate of the striato-pallidal GABAergic neurons leading to motor inhibition, see (Surmeier, 2007). Moreover, the D2R agonist-induced reduction of firing rates in the DA terminal denervated striatum is enhanced by A2AR antagonists and attenuated by A2AR agonists (Stromberg et al, 2000).

There also exist reciprocal antagonistic interactions within A2A-D2 heteroreceptor complexes as D2R can inhibit the A2AR-induced increase in CAMP accumulation via $\mathrm{Gi} / \mathrm{o}$ at the level of the adenylate cyclase (AC), an interaction which can also take place as a cross-talk between $\mathrm{A} 2 \mathrm{AR}$ and $\mathrm{D} 2 \mathrm{R}$ mono-dimers. An antagonistic allosteric D2-A2A receptor-receptor also exists at the level of A2AR recognition in the heteroreceptor complex (FernandezDuenas et al, 2012). The negative allosteric modulation of the $\mathrm{D} 2 \mathrm{R}$ on A2AR agonist binding has been visualized in real-time mode of FRET and D2R activation partially inhibits and also slows the binding association of the fluorescent A2AR agonist. Removal of the D2R brake on the A2AR signaling should therefore lead to an upstate of the striato-pallidal GABA neurons. In fact, it results in increased protein kinase A (PKA) activity causing increased phosphorylation of $\alpha$-amino-3-hydroxy-5-methyl-4-isoxazole-propionate and $\mathrm{N}$-methyl-D-aspartic acid receptors (NMDA) receptors and of dopamine and cAMP-regulated neuronal phosphoprotein (DARPP-32) at the Thr34 position. The latter action leads to inhibition of protein phosphatase-1 further, which enhances the phosphorylation and the activity of these ion channel receptors.

Based on the use of D2 agonists and L-DOPA in treatment of Parkinson's disease, the discovered antagonistic A2AR$\mathrm{D} 2 \mathrm{R}$ interactions in A2A-D2 heteroreceptor complexes, even with these interactions increased in Parkinson's disease models (Ferre et al, 1991; Fuxe et al, 2003; Fuxe et al, 1993), leads to the proposal and use of A2AR antagonists as antiparkinsonian drugs (Bara-Jimenez et al, 2003; Fuxe et al, 2003; Fuxe et al, 1993; Hauser et al, 2003; Hauser and Schwarzschild, 2005). So far it has not been possible to develop A2AR antagonists, which selectively block the A2AR protomer of the A2A-D2 heteroreceptor complex. Different types of A2AR antagonists have consistently reversed the Parkinsonian deficits in nonhuman primates and rodents (Fuxe et al, 2007c; Hodgson et al, 2010; Morelli et al, 2007; Schwarzschild et al, 2006). A2AR antagonists, like SCH 58261, have been found to dose dependently increase locomotor activity in combination with sub-threshold doses of L-DOPA and D2R agonists in reserpinized mice (Morelli et al, 2007; Tanganelli et al, 2004). Such results can be elegantly explained by the hypothesis that A2AR antagonists can target the A2A-D2 heteroreceptor complex and increase $\mathrm{D} 2 \mathrm{R}$ recognition, $\mathrm{D} 2 \mathrm{R}-\mathrm{G}$ protein coupling and D2R signaling in these heteromers.

In an early clinical trial (Bara-Jimenez et al, 2003), it was found that the addition of the $\mathrm{A} 2 \mathrm{~A}$ receptor antagonist istradefylline to a low dose L-DOPA infusion increases the therapeutic response to a level found with an optimal LDOPA infusion dose. At the same time, the degree of dyskinesias is reduced. These results open up the possibility that with combined treatment with oral L-DOPA and istradefylline, a lower dose of L-DOPA can be used to obtain an optimal antiparkinson action associated with a 
lowering of dyskinesias. The same year (Hauser et al (2003) found in a randomized trial in advanced Parkinson's disease that the combined treatment left the dyskinesias more or less unchanged in the presence of a reduction of OFF time. Today, the available clinical data in moderate to advanced Parkinson's disease with the $\mathrm{A} 2 \mathrm{~A}$ receptor antagonists istradefylline and preladenant do not show a reduction of L-DOPA induced dyskinesias (Hauser, 2011; Knebel et al, 2011; Morelli et al, 2012) despite evidence from animal models of Parkinson's disease that $\mathrm{A} 2 \mathrm{~A}$ antagonists can prevent the development of L-DOPA induced dyskinesias and attenuate apomorphine induced dyskinesias (Bibbiani et al, 2003).

Based on our hypothesis, treatment with an A2AR antagonist alone should in fact produce only weak to moderate effects in PD except during early stages of PD when DA is still being released from large numbers of remaining DA terminals. This hypothesis states that the major action of $\mathrm{A} 2 \mathrm{~A}$ antagonists may be to increase the $\mathrm{D} 2 \mathrm{R}$ signaling in the A2A-D2 heteroreceptor complex. Therefore, the A2AR antagonist should ideally be given in early stages of Parkinsonin's disease in combination with close to threshold doses of L-DOPA and/or D2R agonists. Clinical results observed so far are in agreement with this view. Therefore, the A2AR antagonist may act mainly by targeting the A2AR protomer of the A2AR-D2R heteroreceptor complex to enhance $\mathrm{D} 2 \mathrm{R}$ protomer signaling.

A2AR antagonists may therefore enhance D2R protomer signaling at the soma-dendritic level of the striato-pallidal GABA/enkephalin pathway, which leads to a reduction in its activity, reduced motor inhibition and increased motor drive. A combined treatment with L-DOPA, but not with D2R agonists, is optimal as L-DOPA restores D1R activity in the direct pathway that helps motor initiation (Fuxe et al, 2010; Morelli et al, 2012). The direct pathway becomes integrated with the indirect pathway in the globus pallidus interna and zona reticulata of the substantia nigra to optimally inhibit their GABA projections to the motor thalamus. In this way, the GABA inhibition of the excitatory glutamate thalamo-cortical pathway to the motor cortices will be removed and movements restored.

Another advantage of using combined treatment with L-DOPA and an A2A receptor antagonist is that DA formed from L-DOPA, unlike a D2R agonist, can probably activate all the DA receptor subtypes, which should all show deficits in DA receptor signaling in the forebrain of Parkinson's disease patients. Furthermore, also A2A-D3 and A2A-D4 heteroreceptor complexes probably exist in the human brain possessing antagonistic A2A-D3 and A2A-D4 receptorreceptor interactions, which can also be blocked by A2A receptor antagonists (Fuxe et al, 2005; Torvinen et al, 2005). It is therefore postulated that combined treatment with $\mathrm{A} 2 \mathrm{~A}$ antagonists and threshold doses of L-DOPA in early Parkinson's disease may substantially enhance the therapeutic benefits of L-DOPA treatment in this disease with the potential to also reduce dyskinesia development.

As discussed there is also a reciprocal interaction by which $\mathrm{D} 2 \mathrm{R}$ inhibits $\mathrm{A} 2 \mathrm{~A}$ recognition and A2AR signaling at the level of adenylate cyclase either linked to the A2A-D2 heteroreceptor complex or located between A2AR homoreceptor and D2R homoreceptor complexes. Through such mechanisms we can understand why A2AR antagonists alone can counteract haloperidol-induced catalepsy, namely by blocking the excessive A2AR signaling that results from the removal of the inhibitory $\mathrm{D} 2 \mathrm{R}$ signaling through the D2R-blocking action of haloperidol. This mechanism can also help explain some therapeutic effects of A2AR antagonists in advanced PD.

It may be of interest to discuss the possible role of adenosine mechanisms in the reduction of the therapeutic effects of L-DOPA and the appearance of L-DOPA-induced dyskinesias after long-term treatment. Our hypothesis is that upon chronic treatment a L-DOPA induced cointernalization of A2A-D2 heteroreceptor complexes and downregulation of D2R monomers and homoreceptor complexes leads to a dominance of A2AR signaling, which also involves an activation of $A 2 A R$ gene expression via D2R-induced activation of the MAPK pathway (Fuxe et al, 2007c). In support of this hypothesis, increases of A2AR mRNA and A2AR immunoreactivity (IR) have also been demonstrated in animal models of L-DOPA-induced dyskinesias and in brains from dyskinetic PD patients, see Antonelli et al (2006). The resulting upregulation of A2AR leads to increases in PKA and phosphorylated DARPP-32 at Thr34 and increased inhibition of PP-1. This will result in an increase in protein phosphorylation including ion channels, which may help stabilize pathological RM formed under the influence of the transcriptional panorama caused by the L-DOPA-induced excessive D2R activation (Fuxe et al, 2007c). This may lead to a repeated appearance of an abnormal and fixed pattern of firing in the striato-pallidal GABA pathway, which could contribute to dyskinesia development through the indirect pathway to the motor cortex via the motor thalamus. This hypothesis can help explain the reported failure of A2AR antagonists to increase dyskinesias in spite of antiparkinson actions, which cannot be explained by the enhancement of D2-protomer signaling in the A2A-D2 heteroreceptor complex, as this would worsen dyskinesias. We have also postulated based on this hypothesis that A2AR antagonists may help counteract the disappearance of the therapeutic effects of L-DOPA after long-term treatment by counteracting the disbalance of $\mathrm{A} 2 \mathrm{~A}$ versus D2R signaling (Fuxe et al, 2007b; Fuxe et al, 2007c).

Taken together, the demonstrated anti-Parkinsonian effect of A2AR antagonists in clinical studies has given strength to the concept that modulation of allosteric receptor-receptor interactions in heteroreceptor complexes can lead to the development of novel therapies. The work of the Schwarzschild et al (2006) has also given indications for neuroprotective effects of A2AR antagonists in Parkinson's disease based on studies in animal models of Parkinson's disease. Epidemiological evidence also exists for an inverse association between intake of coffee and caffeine in Japanese-American men and the risk of development of Parkinson's disease. 
A2A-D2 AND mGLu2-5-HT2A

HETERORECEPTOR COMPLEXES AND

THEIR RECEPTOR-RECEPTOR

INTERACTIONS IN RELATION TO

SCHIZOPHRENIA AND AS TARGETS FOR

ANTIPSYCHOTIC DRUGS

The probable existence of A2A-D2 heteroreceptor complexes with antagonistic A2A-D2 receptor-receptor interactions in the ventral striato-pallidal GABA pathway (Borroto-Escuela et al, 2013; Diaz-Cabiale et al, 2001; Fuxe et al, 1993; Fuxe et al, 1998) introduced the strategy of using A2A agonists for schizophrenia treatment based on these antagonistic interactions, which leads to a reduction in the affinity of the high-affinity state of the D2R (Fuxe et al, 2005; Fuxe et al, 1998; Fuxe et al, 2010). The classical treatment for schizophrenia is the use of DA receptor antagonists like haloperidol and chlorpromazine (typical antipsychotic drugs) blocking the postjunctional DA receptors of the nigro-striatal and mesolimbic DA neurons as first indicated by Carlsson and Lindqvist (1963) and Carlsson (1988). This work has been further extended in functional and biochemical experiments (Anden et al, 1966). Fuxe (1970) a dysfunction of the meso-limbic DA neurons may be involved in mental disorders like schizophrenia and therefore DA receptors in meso-limbic DA transmission may be a major target for antipsychotic drugs most likely by improving the emotional state of the schizophrenic patients.

Later on the evidence obtained indicates that the D2R subtype is the key target for the typical antipsychotic drugs, its blockade leading to antipsychotic effects. D2R occupancy in the brains of schizophrenic patients also correlates with the antipsychotic effects (Farde et al, 1988). Indications for enhanced striatal DA responsitivity have been obtained in schizophrenic patients with PET imaging (Laruelle et al, 1996). According to the Seeman hypothesis of schizophrenia (Seeman, 2006), the major error in psychosis is an increased proportion of $\mathrm{D} 2 \mathrm{R}$ in the high-affinity state resulting in an increase in D2R recognition and signaling. This makes our proposal on the antipsychotic potential of $\mathrm{A} 2 \mathrm{~A}$ agonist drugs of special interest, as A2A agonists targeting the A2A/D2R mosaic can preferentially reduce the affinity of the high-affinity agonist state of the D2R in the dorsal and ventral striatum (Fuxe et al, 1998).

The glutamate hypothesis of schizophrenia states that the meso-limbic DA neurons are hyperactive due to reduced NMDA receptor function (Jentsch and Roth, 1999; Svensson, 2000), which leads to reduced activity in the descending cortical glutamate projections to the ventral tegmental area. This results in an increased activity of the meso-limbic DA systems. The reason is that a reduced drive develops in the inhibitory ventral tegmental area GABA interneurons, which causes an increased firing in the mesolimbic DA neurons. The meso-limbic DA neurons therefore become hyperactive with increased inhibition of the ventral striato-pallidal GABA pathway (Fuxe et al, 2008b; Svensson,
2000). The ventral striato-pallidal GABA neurons integrate and transfer the emotional information from the limbic system via the mediodorsal thalamic nucleus to the prefrontal cortex. The increased activity of the D2R in the ventral striatum via this brain circuit reduces the glutamate drive to the prefrontal cortex, which worsens the hypoglutamatergic state in schizophrenia.

A2A agonists may be antipsychotic drugs mainly by antagonizing the D2R signaling in the A2A-D2 heteroreceptor complex in the soma-dendritic region and possibly also in the terminal region of the ventral striato-pallidal GABA pathway, which brings its GABA transmission back and leads to increased glutamate drive from the mediodorsal thalamic nucleus to the prefrontal cortex (Groenewegen, 1988). A2AR agonists strongly reduce the D2R agonist-binding affinity and probably also the D3 agonist-binding affinity in nucleus accumbens shell and core (Diaz-Cabiale et al, 2001; Torvinen et al, 2005). They diminish both D2R recognition and Gi/o coupling and potentially also the D3-mediated signaling in this region (Fuxe et al, 2008b). D3 antagonists may also have antipsychotic actions (Schwartz et al, 2000).

The A2A agonist also increases glutamate release in the nucleus accumbens in part via actions on the glutamate terminals (Fuxe et al, 2008b; Popoli et al, 1995), which will also contribute to increasing the excitability of the ventral striato-pallidal GABA pathway after A2A agonist treatment and thus to the antipsychotic activity of A2A agonists. It is important to point out that D2 autoreceptors are not directly modulated by A2AR agonists unlike D2R antagonists known to also block D2 autoreceptors and increase DA release. Instead A2A receptors do not exist in the DA terminal networks leaving the D2 autoreceptor function intact to reduce DA release (Fuxe et al, 2003).

A2A agonist treatment represents a new strategy for schizophrenia treatment especially in combination with low doses of atypical and/or typical D2R antagonists, which should produce antipsychotic actions in the presence of reduced extrapyramidal and other side effects provided the A2A-D2 heteroreceptor complex is the correct target. This may in fact be the case since the antagonistic A2AR-D2R interactions modulate the ventral striato-pallidal GABA pathway controling the glutamate projections to the prefrontal cortex via the ventral pallidum and the mediodorsal thalamic nucleus, a circuit with major disturbances in schizophrenia. Popken et al (2000) demonstrated that there is a subnucleus specific loss of nerve cells in the mediodorsal thalamus of schizophrenics. A 30\% loss of nerve cells can be seen in the mediodorsal thalamic nucleus mainly confined to the parvocellular and densocellular subnuclei. The parvocellular part projects to the dorsolateral parts of the prefrontal cortex and other regions known to be compromised in schizophrenia (Popken et al, 2000). These results underline the relevance of the current antipsychotic strategy of targeting the A2A-D2 heteroreceptor complex in the nucleus accumbens. 
A cortical mGlu2-5-HT2A heteroreceptor complex has been identified and implicated in psychosis (GonzalezMaeso et al, 2008). Previously, metabotropic glutamate $2 / 3$ receptors were regarded as targets for antischizophrenic drugs (Aghajanian and Marek, 2000). In addition, a positive allosteric modulator of mGluR2, biphenyl-indanone $\mathrm{A}$ is effective in a hallucinogenic drug model of psychosis (Benneyworth et al, 2007). Furthermore, a randomized phase II clinical trial in schizophrenia using a mGluR2/3 agonist indicates their possible therapeutic potential for this disease (Patil et al, 2007).

It is of interest to note that the hallucinogenic 2,5dimethoxy- 4-iodoamphetamine (DOI) stimulated [35S]GTPgammaS binding in primary cortical membranes, when linked to either Gai1, Gai2, or Gai3, is strongly reduced by the mGluR2/3 agonist LY379268 as is the hallucinogen-specific induction of egr-2 in mouse cortex (Gonzalez-Maeso et al, 2008). In contrast, the DOI-stimulated [35S] GTPgammaS binding when linked to Gaq/11 is only weakly affected by the mGluR2/3 agonist. Therefore, the mGluR2/3 agonist may in part produce their potential antipsychotic effects by targeting the mGlu2-5-HT2A heteroreceptor complex most likely located in distinct pyramidal and granular cells and reduce the hallucinogenspecific Gi/o signaling via allosteric interactions over the receptor interface (Gonzalez-Maeso et al, 2008).

An interesting consequence of restoring the glutamate drive to the prefrontal cortex by A2A agonists/D2R antagonists may in part be the increased activation of cortical mGluR2 possibly in part located in the mGlu2-5HT2A heteroreceptor complex in cortical neurons. This may reduce the hallucinogenic-specific Gi/o signaling and behavior over the 5-HT2A receptor protomer with a reduction of primary disturbances in cortical sensory processing (Gonzalez-Maeso et al, 2008). Recently, this group identified three residues located at the intracellular end of transmembrane four of the mGlu2 receptor, which are necessary for this receptor heteromerization to take place (Moreno et al, 2012). Upon substitution of these residues, the mGlu2-5-HT2A heteroreceptor complex is no longer formed, which is associated with a reduction in the psychosis-like effects induced in mice by hallucinogenic 5HT2A agonists. Furthermore, the active conformation of the 5-HT2A receptor is increased in the postmortum prefrontal cortex from schizophrenic subjects (Muguruza et al, 2012). It would be of interest to know if this dysregulation of 5HT2A receptor recognition also involves the 5-HT2A protomer of a mGlu2-5-HT2A heteroreceptor complex of the human prefrontal cortex.

It may be speculated that in one group of schizophrenic patients, the heteroreceptor complex pathology could mainly exist, eg, in the cortical mGlu2-5-HT2A heteroreceptor complex. Therefore, these schizophrenic patients may have enhanced therapeutic responses to treatment with mGluR2 agonists and/or 5-HT2A antagonists with regard to antipsychotic activity. Other groups of schizophrenic patients may instead show improved therapeutic responses by targeting a postulated and malfunctioning D2-5-HT2A heteroreceptor complex in the ventral striatum. It has been shown that the D2R and the 5-HT2AR likely form stable and specific heteromers when expressed in HEK293T mammalian cells (Borroto-Escuela et al, 2010e; Lukasiewicz et al, 2010). Targeting both heteroreceptor complexes is also an interesting option which may already take place in the clinic, as many atypical antipsychotics like risperidone block inter alia both $\mathrm{D} 2 \mathrm{R}$ and especially 5-HT2A receptors in clinically effective doses. Inverse 5-HT2A agonists also enhance the actions of atypical antipsychotic drugs (Meltzer and Massey, 2011).

\section{A2A-D2 AND D2-NMDA HETERORECEPTOR COMPLEXES AND THEIR RECEPTOR-RECEPTOR INTERACTIONS IN RELATION TO COCAINE ADDICTION AND AS TARGETS FOR DRUGS AGAINST COCAINE ADDICTION}

Adenosine has an important modulatory role in accumbal/ striatal function. Adenosine A2ARs are concentrated in these brain regions more than anywhere else in the brain and directly regulate the release of glutamate and the activity of the striato-pallidal GABA neurons (Fuxe et al, 2007b; Fuxe et al, 2010). In accordance with these neuroanatomical and neurochemical links, it has been demonstrated that central reward processes are modulated by $A 2 A R$ function. As such, activation of A2ARs inhibits brain stimulation reward and cocaine withdrawal by elevating current reward thresholds without apparently affecting performance, whereas the blockade of A2ARs reverses the reward impairment produced by cocaine withdrawal (Baldo et al, 1999). The blockade of adenosine receptors by caffeine, its main mechanism of action is antagonizing $\mathrm{A} 1 \mathrm{R}$ and $\mathrm{A} 2 \mathrm{AR}$, leads to a more rapid acquisition of cocaine self-administration in rats (Horger et al, 1991). Thus, specific antagonists acting at these receptors lead to high levels of cocaine-lever selection in substitution tests and produce a leftward shift in the cocaine dose-response curve, and the administration of a selective A2AR antagonist (MSX-3) enhances the expression of cocaine sensitization (Filip et al, 2006). In contrast, rats pre-exposed to A2AR agonists show a reduced initiation of cocaine self-administration (Knapp et al, 2001). We have found an increase in A2ARs in the nucleus accumbens after extended cocaine self-administration (Marcellino et al, 2007). This effect is strictly dependent on active selfadministration since yoked controls that get passively infused with cocaine show different alterations in a state and brain region dependent way (Frankowska et al, 2012), which provides a rational for the aforementioned pharmacological interventions.

A2AR ligands have also been tested in the reinstatement paradigm, which provides a measure for drug-seeking and thus models the motivational aspects of craving. The A2AR 
antagonist CGS 15943 reinstates cocaine-seeking behavior and maintains self-administration in baboons (Weerts and Griffiths, 2003), whereas pre-treatment with the A2AR agonist CGS 21680 dose-dependently blunts cocaine- and cue-induced reinstatement of drug-seeking behavior without affecting sucrose seeking (Bachtell and Self, 2009). These studies show that A2AR activation via A2AR agonists can reduce cocaine-seeking behavior. This conclusion is further supported by the fact that pharmacological stimulation of A2ARs protects against both the development and expression of cocaine sensitization (Filip et al, 2006).

Other studies utilizing genetic deletion of the A2ARs report findings that at first glance to conflict with pharmacological intervention studies. Mice lacking the A2AR display attenuated locomotor responses to cocaine and reduced reinforcing efficacy in cocaine self-administration (Chen et al, 2003; Soria et al, 2006). These opposing findings are most likely due to the lack of neuroanatomical specificity of knock-out of A2AR in neural circuits regulating cocaine-induced behaviors. In fact, conditional mouse models support this, as striatal-specific knock-out of A2ARs enhances the effects of cocaine, whereas more widespread forebrain knock-out of A2ARs reduces cocaineinduced locomotion (Shen et al, 2008). In conclusion, stimulation of A2ARs in accumbal/dorsal striatal sites may reduce cocaine-seeking behavior.

A large number of studies have dealt with the role of the mesocorticolimbic and nigrostriatal dopamine neurons and their D1, D2, and D3 receptors in mediating a variety of cocaine effects relevant for the development of addictive behavior (Everitt et al, 2008; Spanagel and Weiss, 1999; Wise, 2009). In particular, stimulation of D2Rs in the nucleus accumbens and the dorsal striatum is involved in mediating the behavioral effects of cocaine and these actions are antagonized by activation of A2ARs (Durieux et al, 2009; Filip et al, 2006; Soria et al, 2006). The higher the addicted cocaine state the higher the degree of D2like agonist induced relapse following chronic cocaine selfadministration indicating a major role of D2like receptor sensitization in cocaine addiction (Self, 2010). It is further known that DA transmission can be reduced by A2AR agonists, while A2AR antagonists increase it. It is suggested that striatal A2A-D2 heteroreceptor complexes and their antagonistic receptor-receptor interactions contribute to these effects.

An increase in functional $\mathrm{A} 2 \mathrm{~A}$ receptors in the nucleus accumbens was observed after extended cocaine selfadministration in Sprague-Dawley rats (Marcellino et al, 2007). This 10 day cocaine self-administration procedure produces increases in extracellular DA levels and the resulting increase in DA receptor signaling gives rise to an upregulation of functional $\mathrm{A} 2 \mathrm{~A}$ receptors likely mainly present in the ventral striato-pallidal GABA neurons of this region. The disappearance of the $\mathrm{A} 2 \mathrm{AR}$ upregulation during the withdrawal period may help explain the increased reinforcing efficacy of cocaine in the 7-day withdrawal group (Morgan et al, 2002). The mechanism may involve increased signaling via nucleus accumbens $\mathrm{D} 2 \mathrm{R}$ and D3 receptors by reducing the $\mathrm{A} 2 \mathrm{AR}$ brake on $\mathrm{D} 2 \mathrm{R}$ and $\mathrm{D} 3 \mathrm{R}$ signaling (Marcellino et al, 2007). The results indicate a possible role of antagonistic receptor-receptor interactions in accumbens A2A-D2 and A2A-D3 heteroreceptor complexes and/or at the level of adenylate cyclase in the prevention and/or treatment of cocaine addiction.

In support of a role of antagonistic A2A/D3 interactions (Fuxe et al, 2005; Torvinen et al, 2005) in cocaine actions in the nucleus accumbens (Marcellino et al, 2007) D3 receptor antagonists also counteract cocaine seeking and cocaine enhanced reward and may be used in treatment of cocaine addiction (Vorel et al, 2002). An upregulation of D3 mRNA levels has been found in reward networks of human cocaine fatalities. Therefore, the reduction not only of the antagonistic A2A/D2R interaction but also of antagonistic A2A/ D3 interaction in the 7-day cocaine withdrawal group (Marcellino et al, 2007) may contribute to the increased motivation to self-administer cocaine in the 7-day cocaine withdrawal group (Morgan et al, 2002). These results indicate that $\mathrm{A} 2 \mathrm{~A}$ agonists can represent cocaine antagonists to be used in the prevention and treatment of cocaine addiction. A2AR-D2R heteroreceptor complexes are hypothesized to be critically involved in cocaine addiction, and more specifically that the activation of the A2AR protomer of the heteroreceptor complex inhibits the development of addictive behavior.

The observed increase of $\mathrm{A} 2 \mathrm{~A}$ receptor density in nucleus accumbens after extended cocaine self-administration may depend on the existence of an atypical CRE in the core promotor of the $\mathrm{A} 2 \mathrm{~A}$ receptor gene (Chiang et al, 2005). CREB (CRE-binding protein) diminishes cocaine reward in this region (Carlezon et al, 1998) and is enabled by increased activation of the extracellular signal-related kinase (Mattson et al, 2005). Cocaine-induced activation of D2-like receptors can produce an increase in CREB phosphorylation via several intracellular mechanisms (Marcellino et al, 2007).

It should be considered that the $\mathrm{A} 2 \mathrm{~A}$ receptor upregulation reflects not only increases in, eg, A2A-D2 like heteroreceptor complexes and/or their antagonistic receptor-receptor interactions but also in increased presence of A2AR monomers and formation of A2A homoreceptor complexes. They may all increase the excitability of the striato-pallidal GABA neurons (Antonelli et al, 2006; Fuxe et al, 2007b) thus opposing D2like inhibition of these neurons. Another mechanism could be that the persistent D2R-like activation sensitizes A2A signaling at the level of the $\mathrm{AC}$ via release of $\beta \gamma$ dimers from the activated $\mathrm{Gi}$ proteins (Vortherms and Watts, 2004), leading to a dominance of A2AR signaling.

By comparing the cocaine self-administration group with the 'yoked' cocaine group in Wistar rats evidence has been obtained for the existence of motivational mechanisms that guide adaptive changes in the A2AR and D2R and in the D2R-Gi coupling, which differentially developed in the ventral and dorsal striatum during cocaine maintenance 
and extinction (Frankowska et al, 2012). Differences observed in the adaptive changes occurring in $\mathrm{A} 2 \mathrm{~A}$ and $\mathrm{D} 2 \mathrm{R}$ in response to cocaine self-administration of SpragueDawley and Wistar rats may, in addition to genetic differences, also result from differences in the cocaine self-administration schedule used, namely in the doses of cocaine administered, the total cocaine intake per animal and the schedule of cocaine reinforcement (Frankowska et al, 2012).

Filip et al (2012) have extensively discussed the importance of $\mathrm{A} 2 \mathrm{AR}-\mathrm{D} 2 \mathrm{R}$ interactions in drug addiction in general. Behavioral studies indicate that A2A agonists may block drug abuse reinstatement in general as well as actions of withdrawal from drugs of abuse but the mechanisms still remain to be explored in the context A2A-D2 heteroreceptor complexes versus A2A receptor monomers and $\mathrm{A} 2 \mathrm{~A}$ homoreceptor complexes.

Our working hypothesis is that A2AR-D2R heteroreceptor complexes in the ventral striatum are critically involved in cocaine addiction, and more specifically that the activation of the $\mathrm{A} 2 \mathrm{AR}$ protomer of this heteroreceptor complex inhibits the development of addictive behavior. A2A agonists are therefore a viable option for treatment of cocaine addiction, with special emphasis placed on the development of A2A agonists that preferentially target the A2A protomer in this heteroreceptor complex. A combined treatment with low doses of A2A agonists and D2 amtagonists will also be tested and should lead to synergistic effects as to counteract cocaine addiction development. The functional role of striatal A2A-D2 heteroreceptor complexes and their ratios with striatal $\mathrm{A} 2 \mathrm{AR}$ or $\mathrm{D} 2 \mathrm{R}$ populations remains to be characterized in the course of the addiction cycle involving the progression from the onset of cocaine taking behavior to the maintenance phase and sub-sequent addicted versus nonaddicted stage.

The D2R and NMDA receptors form D2-NMDA heteroreceptor complexes (Figure6) through the IC3 loop of D2R interacting with the NR2B subunit (Liu et al, 2006) leading to inhibition of NMDA receptor signaling in the striatal glutamate synapses. This interaction is enhanced by cocaine and the D2R/NR2B interaction has been shown to be critical for the full behavioral response to acute cocaine treatment (Liu et al, 2006). It is therefore suggested that enhancers of signaling in NR2B containing NMDA receptors in combination with low doses of D2R antagonists may be of value cocaine addiction for treatment. Otherwise the cortical control of the striatum would be markedly reduced and the striato-pallidal GABA neurons will become silenced by cocaine-induced D2R activation involving the mesolimbic and nigrostriatal DA neurons unopposed by NMDA synapses and cocaine addiction may develop.

To stop the pathological control by enhanced D2R signaling of the ventral and dorsal striato-pallidal GABA pathways, both the extrasynaptic A2A-D2 and synaptic D2NMDA heteroreceptor complexes should be targeted. This may, eg, be possible by low doses of D2R antagonists
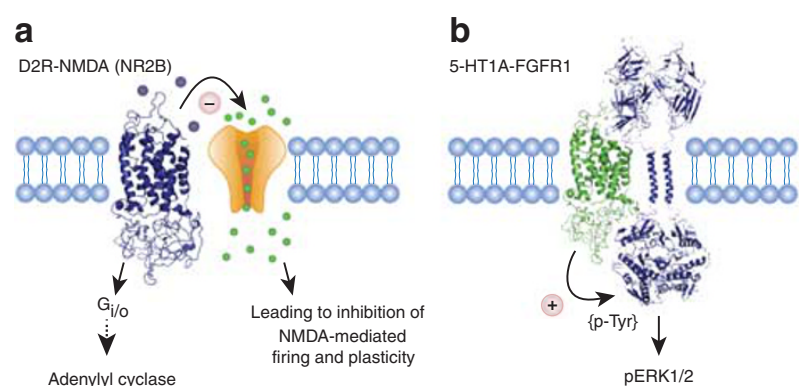

Figure 6. Receptor-receptor interactions in different types of heteroreceptor complexes in the CNS have now been obtained. The heteroreceptor complexes may allow direct physical interactions between the receptors with allosteric receptor-receptor interactions between them. The schematic representation depicts some of the principal, nonexclusive, molecular mechanisms by which GPCR heteromers produce novel functions or modulation. (a) Ion channel receptor-GPCR heteroreceptor complexes and their receptor-receptor interactions. Direct interaction of the dopamine D2R with the NMDA (NR2B unit) receptor leads to a D2-mediated inhibition of the NMDA receptor signaling with reduction of NMDA receptor-dependent firing and plasticity. (b) Receptor tyrosine kinase (RTK)-GPCR heteroreceptor complexes and their receptor-receptor interactions. Transactivation can occur during signal initiation and propagation, using shared signaling pathways. In the case of GPCRs, they can use RTK themselves as signaling platforms via direct receptor-receptor interactions. A heteroreceptor complex between $5 \mathrm{HT} 1 \mathrm{~A}$ receptor and FGFR1 has recently been discovered in the rat hippocampus and the midbrain raphe nuclei. In vitro assays on extracellular signal-regulated kinases 1 and 2 phosphorylation demonstrated synergistic increases in signaling and structural plasticity in the hippocampus and mesencephalic raphe through the allosteric receptorreceptor interactions.

characterized to reduce $\mathrm{D} 2 \mathrm{R}$ protomer signaling in both heteroreceptor complexes in combination with A2A agonists, which target and reduce the $\mathrm{D} 2 \mathrm{R}$ protomer signaling in the A2A-D2 heteroreceptor complexes. This treatment should also reduce development of side effects as the combined treatment may allow low doses to be used to restore firing of the striato-pallidal GABA neurons through reduction of $\mathrm{D} 2 \mathrm{R}$-mediated inhibition.

\section{FGFR1-5-HT1A HETERORECEPTOR COMPLEXES AND THEIR RECEPTOR-RECEPTOR INTERACTIONS IN DEPRESSION AND AS TARGETS FOR ANTIDEPRESSANT DRUGS}

The focus of research into antidepressant drug action has shifted in recent years towards their gradually developing effects on intraneuronal signal transduction and cellular plasticity (Coyle and Duman, 2003; Manji and Duman, 2001). Several findings suggest that antidepressants facilitate activity-dependent selection of functional synaptic connections in the brain, and through their neurotrophic effects improve information processing within neuronal-glial networks compromised in mood disorders (D'Sa and Duman, 2002). According to such a 
view, antidepressants induce processes of neuroplasticity that lead to a reorganization of central neural networks, which generates their therapeutic effects (Duman, 2002b; Nestler et al, 2002).

Increasing evidence suggests that antidepressant drugs via actions on the 5-HT and NA neurons may exert their therapeutic activity, at least in part, through the enhancement of neurotrophic factor expression and function (Duman, 2002a; Saarelainen et al, 2003). In this context, several lines of converging evidence suggest that brain-derived neurotrophic factor and its RTK trkB have a central role in the mechanism of antidepressant action, including electroconvulsive shock treatment (D'Sa and Duman, 2002; Nestler et al, 2002; Saarelainen et al, 2003; Shirayama et al, 2002).

Recently, an involvement of the fibroblast growth factors (FGFs) was proposed in mood disorders (Turner et al, 2006). Antidepressant drugs and chronic electroconvulsive shock treatment may increase the expression of fibroblast growth factor-2 (FGF-2) in frontal cortices and hippocampus (Mallei et al, 2002; Maragnoli et al, 2004), which suggests that potentially the FGF-2 expression could also mediate the antidepressant effects. In line with these results, chronic antidepressant treatment increases neurogenesis in adult rat hippocampus and depression is associated with reduced cortical thickness and neuronal size (Rajkowska et al, 1999).

The hippocampal atrophy found in major depression may be involved in the pathophysiology of this disease in view of the critical role of the hippocampus (Hip) in the emotional networks (Castren et al, 2007; Rajkowska et al, 1999; Schmidt and Duman, 2007). The atrophy may result from the downregulation of neurotrophic factors in the Hip. FGF2 mRNA levels in the hippocampus are reduced in major depression (Charney and Eric, 2008) and this region appears to show an especially strong atrophy (Charney and Eric, 2008). Treatment with antidepressant drugs in rodents can increase Hip FGF-2 levels (Schmidt and Duman, 2007). The therapeutic effect of the most commonly prescribed antidepressants, like the selective serotonin reuptake inhibitors (SSRIs), eg, fluoxetine and the 5-HT1A partial agonist Buspirone (Carlsson et al, 1968; Wong et al, 1995), may in part be related to the enhancement of 5-HT transmission in the Hip mainly involving the postjunctional 5-HT1A receptor.

There is evidence for the existence of heteroreceptor complexes, which even in the absence of neurotrophic factor binding to the RTK, can lead to transactivation of RTKs with effects on neuronal plasticity (Flajolet et al, 2008; Fuxe et al, 2007b; Lee and Chao, 2001; Luttrell et al, 1999).

In our paper (Borroto-Escuela et al, 2012a) evidence is given for the existence of FGFR1-5-HT1A heteroreceptor complexes, using BRET, coimmunoprecipitation, and the PLA with a partial characterization of their interface (Figure 6). Evidence is given for their involvement in enhancement of hippocampal neuroplasticity in the rat (Borroto-Escuela et al, 2012a). In vitro and in vivo studies reveal a 5- HT1A agonist induced phosphorylation of
FGFR1 and extracellular signal-regulated kinase (ERK) 1/2 in rat hippocampus without changing FGF2 levels. Coactivation of the heteroreceptor complex also results in synergistic increases in extensions of PC12 cells and neurite densities and protrusions in primary hippocampal cultures dependent on the receptor interface. The structural plasticity is linked to synergistic increases in ERK1/2 signaling upon coactivation with fibroblast growth factor 2 (FGF-2) and a 5-HT1A agonist, and dependent on the heteroreceptor interface. We have also found that acute and a 10 day i.c.v. treatment with FGF-2 and the 5-HT1A agonist 8-OHDPAT in the Sprague-Dawley rat can produce synergistic antidepressant effects in the forced swim test. Neurotrophic and antidepressant effects of 5-HT in brain may therefore, in part, be mediated by activation of the 5-HT1A receptor protomer in the hippocampal FGFR1-5HT1A heteroreceptor complex, which enhances the FGFR1 signaling via receptor-receptor interactions. Therefore, this cotreatment may result in more rapid and stronger antidepressant actions than found with SSRIs.

Evidence is also presented for the existence of FGFR1-5HT1A heteroreceptor complexes with facilitatory receptorreceptor interactions in the mesencephalic raphe 5-HT nerve cells with relevance for neuroplasticity. The raphe 5-HT1A autoreceptor, when being part of the FGFR1-5HT1A heteroreceptor complex, may therefore have a beneficial role in depression, its activation leading to a FGFR1 transactivation through an allosteric receptorreceptor interaction. This can assist in the recovery of 5-HT nerve cell trophism including 5-HT synthesis and storage as well as increased outgrowth of dendritic, and terminal networks in the raphe-hippocampal 5-HT neuronal system. These results indicate that the 5-HT1A autoreceptors may have a trophic role in the midbrain raphe 5-HT neuronsystems by being part of a FGFR1-5-HT1A receptor heterocomplex in the midbrain raphe 5-HT nerve cells, in addition to having a key role in reducing the firing of these neurons. Future work will show whether this hypothesis is relevant for understanding mechanisms of major depression.

The receptor-receptor interaction in the FGFR1-5-HT1A heteroreceptor complex may change preferred signaling pathways of the individual receptors and lead to biased signaling and/or altered receptor trafficking and/or recognition, which may provide targets for the development of novel antidepressants.

The results obtained underline a role of RTK-GPCR heteroreceptor complexes in depression and its treatment and that transactivation of RTK by GPCRs (Lee and Chao, 2001; Luttrell et al, 1999) can occur via facilitatory receptorreceptor interactions in such complexes, namely in the FGFR1-5-HT1A heteroreceptor complex as postulated in 2007 (Fuxe et al, 2007a). It is certainly possible that in another RTK-GPCR complex antagonistic receptorreceptor with transinhibition of the RTK signaling develops.

In a brilliant paper from Flajolet et al (2008) demonstrate the existence of A2A-FGFR1 heteroreceptor complexes by 
yeast two-hybrid analysis. Coactivation of the A2AR and FGFR1 results in a synergistic activation of the ERK/MAPK pathway, synergistic facilitation of corticostriatal LTP as well as structural signs of enhanced synaptic plasticity. FGF is proposed to act as a co-transmitter through adenosine $\mathrm{A} 2 \mathrm{~A}$ receptor to regulate synaptic plasticity in the striatopallidal GABA neurons (Flajolet et al, 2008). It is of interest that in this case the GPCR A2A operates mainly via Gs/olf while the 5-HT1A receptor in the FGFR1-5-HT1A heteroreceptor complex operates mainly via Gi/o. Nevertheless, a similar strong enhancement of synaptic plasticity develops. One explanation may be that it is the allosteric receptorreceptor interactions in the heteroreceptor complex, which make the synergistic enhancement of synaptic plasticity possible and involve inter alia development of biased agonism.

In view of the presence of A2A-D2 heteroreceptor complexes in the striato-pallidal GABA neurons, the existence of FGFR1-A2A-D2 higher-order heteroreceptor complexes in these neurons may be postulated. It may be speculated in view of the existence of bidirectional antagonistic A2A-D2 receptor-receptor interactions (Fuxe et al, 2007a; Fuxe et al, 2010) that D2R activation can bring down the synergistic enhancement of synaptic plasticity found upon A2A and FGFR1 coactivation. Thus, a dynamic formation of such a heteroreceptor complex may allow a fine tuning of synaptic plasticity in the striato-pallidal GABA neurons of high relevance to their function in the basal ganglia circuits. A dysfunction of such a higher-order heteroreceptor complex may contribute to pathologies found in Parkinson's disease, schizophrenia, and drug addiction.

\section{FUTURE RESEARCH DIRECTIONS}

The D2Rs are regarded as hub receptors, as they participate in many different types of heteroreceptor complexes (of unknown stoichiometry and topology) (Tarakanov et al, 2012b). The standard treatment with L-dopa and/or D2R agonists in PD builds especially on their activation of these $\mathrm{D} 2 \mathrm{R}$ in moderate to high doses and the accessory A2A, mGluR5 and CB1 receptors in the different heteroreceptor complexes are not targeted.

A novel principle may now be used to develop D2R agonists for treatment of Parkinson's disease based on the existence of various D2R heteroreceptor complexes. Thus, the conformational state of the D2R may differ from one heteroreceptor complex to the other one, which may also be due to different types of receptor-protein interactions. It is also influenced by the local molecular histology of the surface membrane of, eg, discrete striato-pallidal nerve cell populations and DA nerve terminal networks.

Thus, the agonist pharmacology of $\mathrm{D} 2 \mathrm{R}$ in terms of potency and efficacy may show substantial differences among various types of heteroreceptor complexes like A2AD2, A2A-D2-mGlu5, D2-NR2B containing NMDA hetero- receptor complexes and also versus D2R monomers and D2 homoreceptor complexes. The development of specific D2R agonist drugs for the D2R short autoreceptor may be especially hopeful, as the D2 autoreceptor isoform not only interacts with other types of receptors but also with special types of proteins like the DA transporter on the DA terminals. A disruption of the DAT-D2R interaction may exist in schizophrenia leading to enhancement of DA release (Lee et al, 2009).

This approach should give exciting possibilities to develop novel and more selective D2R agonist drugs for Parkinson's disease treatment by preferentially acting on certain postjunctional heteroreceptor complexes in, eg, the striato-pallidal GABA neurons and their glutamate inputs. In support of this approach, the striatal D1-D2R heteroreceptor complexes have been shown to possess a unique pharmacology and couples with $\mathrm{Gq} / 11$, as discovered by the group of Dr George and Dr O'Dowd (Rashid et al, 2007a; Rashid et al, 2007b). The DA agonist SKF-83959 is a specific agonist for this heteroreceptor complex by being a full agonist at the D1 receptor and a partial agonist at the pertussis-toxin resistant $\mathrm{D} 2 \mathrm{R}$ protomer in this heteroreceptor complex.

The same principle may also be used to develop novel D2R-based antipsychotics for treatment of schizophrenia. Thus, the potency and efficacy of full and partial D2R antagonists and their inverse D2R agonist activity may vary among the different D2R heteroreceptor complexes due to differences in the conformational state of the participating postjunctional D2R and/or D2 autoreceptors. This can involve the allosteric receptor-receptor interactions in the heteroreceptor complexes giving them differences in D2R antagonist pharmacology.

The major target may be the postjunctional D2R in the ventral striato-pallidal GABA neurons inhibiting the glutamate drive to the prefrontal cortex in view of likely increases in meso-limbic DA activity in schizophrenia (Fuxe et al, 2008b; Svensson, 2000). It should be mentioned that the atypical antipsychotic-like drug remoxipride, unlike haloperidol, in vivo blocks only a subpopulation of $\mathrm{D} 2 \mathrm{R}$ in nigro-striatal and meso-limbic/cortical regions as evaluated by the protection against the $\mathrm{N}$-ethoxycarbonyl-2ethoxy-1,2-dihydroquinoline (EEDQ)-induced decreases in $\mathrm{D} 2 \mathrm{R}$ binding due to its irreversible inactivation of D2R (Ogren et al, 1994). The blockade of this D2R subpopulation in vivo, which may belong to a certain type of $\mathrm{D} 2 \mathrm{R}$ heteroreceptor complex, could be the basis for its atypical antipsychotic-like profile with reduced extrapyramidal side effects. Thus, the underlying mechanism may be that this selective D2R antagonist can only bind and block D2R protomers in distinct D2R heteroreceptor complexes present in these regions due to their unique D2R antagonist pharmacology. This may now be tested by studying how the potency and efficacy of remoxipride in blocking D2R could possibly vary in cell lines upon D2R co-transfection with other receptors known to form heteroreceptor complexes with the D2R (Fuxe et al, 2009). This approach could also be 
developed for the treatment of cocaine addiction where novel and more selective D2R antagonists for certain D2R heteroreceptor complexes in the ventral striatum may also offer treatment improvements.

The other novel principal strategy based on the different $\mathrm{D} 2 \mathrm{R}$ heteroreceptor complexes is the targeting of their accessory receptor protomers antagonistically interacting via receptor-receptor interactions with the $\mathrm{D} 2 \mathrm{R}$ protomer (hub receptor), which involves, eg, the A2A and the mGlu5 receptors. A large number of observations suggest that A2AR and mGluR5 appear to synergize in counteracting $\mathrm{D} 2 \mathrm{R}$ signaling in the postulated A2A-D2-mGluR5 higherorder heteroreceptor complexes in the striatum (Cabello et al, 2009; Ciruela et al, 2012; Fuxe et al, 2008a).

In PD and models of PD it is possible to test low doses of L-dopa and D2R agonists in combination with A2A and/or mGluR5 antagonists to reduce the inhibitory impact of these receptors on $\mathrm{D} 2 \mathrm{R}$ recognition and signaling in $\mathrm{A} 2 \mathrm{~A}-$ D2, A2A-D2-mGlu5 and D2-mGlu5 heteroreceptor complexes. Reduced collateral effects of L-dopa and D2R agonists may be observed despite hypokinesia improvement, resting tremor, and rigidity (Fuxe et al, 2007c; Schwarzschild et al, 2006). In early PD, it may be possible to substantially delay the onset of L-dopa and D2R agonist treatment by introducing monotherapy or combined therapy with A2A and/or mGluR5 antagonists. Combined treatment with L-DOPA should also be tested since then a certain increase in DA signaling may also take place also at D1 and D5 receptors.

However, in schizophrenia and schizophrenia like models, only low doses of typical and atypical antipsychotics may be used in combined treatment with low doses of A2A agonists and/or mGluR5 agonists to obtain reduced collateral effects as these agonists will synergistically reduce D2like signaling by activating the A2A and/or mGluR5 protomers of the D2R heteroreceptor complexes. Therefore, with this combined treatment antipsychotic actions may be obtained with reduced extrapyramidal and other side effects and monotherapy with A2A agonists should also be considered in view of their atypical antipsychotic profile. A similar strategy may also be developed for treatment of cocaine addiction.

A major task for the future will be to characterize the receptor interface in the different types of existing heteroreceptor complexes in the CNS. In this way interface interfering peptides and non-peptide compounds (receptor-receptor interaction inhibitors) may be developed to target the receptor interface and block the dysfunctional receptor-receptor interactions. This will also unravel the function of the different heteroreceptor complexes and their role in disease development in the CNS. It is likely that targeting the receptor interface will be a fruitful avenue for drug development in the mental and neurological diseases. The GPCR-interacting protein field (GIP) faces similar challenges (Bockaert et al, 2010).

In the future research on GPCR heteroreceptor complexes and GIP research should join forces in understanding the full architecture of the molecular world of GPCRs and their interacting proteins and its dynamics in space and time. An increased understanding of the allosteric receptor-receptor interactions is equally important and may be assisted by bimolecular dynamics simulations to create atomic-resolution models of the various receptor interfaces. This type of research in cellular models and in brain tissue should provide exciting developments in novel drugs in neuropschopharmacology.

\section{FUNDING AND DISCLOSURE}

This work was funded by the Grants from the Swedish Research Council (04X-715), Torsten and Ragnar Soderberg Foundation, Hjarnfonden and Marianne and Marcus Wallenberg Foundation to KF, by a Grant from the Swedish Royal Academy of Sciences to DOB-E and by the Grants SAF2011-24779 and Consolider-Ingenio CSD2008-00005 from Ministry of Science and Innovation and ICREA Academia-2010 from the Catalan Institution for Research and Advanced Studies to FC. Dr Romero-Fernandez, Dr. Agnati, Dr. Palkovits and Dr. Tarakanov, declare no potential conflict of interest.

\section{REFERENCES}

Aghajanian GK, Marek GJ (2000). Serotonin model of schizophrenia: emerging role of glutamate mechanisms. Brain Res Brain Res Rev 31: 302-312.

Agnati LF, Ferre S, Lluis C, Franco R, Fuxe K (2003). Molecular mechanisms and therapeutical implications of intramembrane receptor/receptor interactions among heptahelical receptors with examples from the striatopallidal GABA neurons. Pharmacol Rev 55: 509-550. A 20 year history of discoveries of allosteric receptor-receptor interactions among G protein-coupled receptors is given

Agnati LF, Guidolin D, Leo G, Carone C, Genedani S, Fuxe K (2010). Receptorreceptor interactions: A novel concept in brain integration. Progress Neurobiol 90: $157-175$

Agnati LF, Leo G, Genedani S, Andreoli N, Marcellino D, Woods A et al. (2008). Structural plasticity in G-protein coupled receptors as demonstrated by the allosteric actions of homocysteine and computer-assisted analysis of disordered domains. Brain Res Rev 58: 459-474.

Albizu L, Cottet M, Kralikova M, Stoev S, Seyer R, Brabet I et al. (2010). Timeresolved FRET between GPCR ligands reveals oligomers in native tissues. Nat Chem Biol 6: 587-594.

Anden NE, Dahlstrom A, Fuxe K, Larsson K (1966). Functional role of the nigro-neostriatal dopamine neurons. Acta pharmacologica et toxicologica 24 263-274.

Antonelli T, Fuxe K, Agnati L, Mazzoni E, Tanganelli S, Tomasini MC et al. (2006). Experimental studies and theoretical aspects on A2A/D2 receptor interactions in a model of Parkinson's disease. Relevance for L-dopa induced dyskinesias. J Neurol Sci 248: 16-22.

Audet M, Lagace M, Silversides DW, Bouvier M (2010). Protein-protein interactions monitored in cells from transgenic mice using bioluminescence resonance energy transfer. FASEB J 24: 2829-2838.

Bachtell RK, Self DW (2009). Effects of adenosine A2A receptor stimulation on cocaine-seeking behavior in rats. Psychopharmacology 206: 469-478.

Baldo BA, Koob GF, Markou A (1999). Role of adenosine A2 receptors in brain stimulation reward under baseline conditions and during cocaine withdrawal in rats. J Neurosci 19: 11017-11026.

Bara-Jimenez W, Sherzai A, Dimitrova T, Favit A, Bibbiani F, Gillespie M et al. (2003). Adenosine A(2A) receptor antagonist treatment of Parkinson's disease. Neurology 61: 293-296.

Benneyworth MA, Xiang Z, Smith RL, Garcia EE, Conn PJ, Sanders-Bush E (2007). A selective positive allosteric modulator of metabotropic glutamate receptor subtype 2 blocks a hallucinogenic drug model of psychosis. Molecular Pharmacol 72: 477-484. 
Bibbiani F, Oh JD, Petzer JP, Castagnoli N Jr., Chen JF, Schwarzschild MA et al. (2003). A2A antagonist prevents dopamine agonist-induced motor complications in animal models of Parkinson's disease. Exp Neurol 184: 285-294.

Bockaert J, Marin P, Dumuis A, Fagni L (2003). The 'magic tail' of G protein-coupled receptors: an anchorage for functional protein networks. FEBS Lett 546: 65-72.

Bockaert J, Perroy J, Becamel C, Marin P, Fagni L (2010). GPCR interacting proteins (GIPs) in the nervous system: roles in physiology and pathologies. Annu Rev Pharmacol Toxicol 50: 89-109.

Borroto-Escuela DO, Craenenbroeck KV, Romero-Fernandez W, Guidolin D, Woods AS, Rivera A et al. (2010a). Dopamine D2 and D4 receptor heteromerization and its allosteric receptor-receptor interactions. Biochem Biophys Res Commun 404: 928-934.

Borroto-Escuela DO, Marcellino D, Narvaez M, Flajolet M, Heintz N, Agnati L et al. (2010b). A serine point mutation in the adenosine A2AR C-terminal tail reduces receptor heteromerization and allosteric modulation of the dopamine D2R. Biochem Biophys Res Commun 394: 222-227.

Borroto-Escuela DO, Narvaez M, Marcellino D, Parrado C, Narvaez JA, Tarakanov $\mathrm{AO}$ et al. (2010c). Galanin receptor-1 modulates 5-hydroxtryptamine-1A signaling via heterodimerization. Biochem Biophys Res Commun 393: 767-772.

Borroto-Escuela DO, Romero-Fernandez W, Mudo G, Perez-Alea M, Ciruela F, Tarakanov AO et al. (2012a). Fibroblast growth factor receptor 1- 5hydroxytryptamine $1 \mathrm{~A}$ heteroreceptor complexes and their enhancement of hippocampal plasticity. Biol Psychiatry 71: 84-91. Neurotrophic and antidepressant effects of 5-HT in brain may, in part, be mediated by activation of the 5-HT1A receptor protomer in the hippocampal FGFR1-5-HT1A heteroreceptor complex enhancing FGFR1 signaling

Borroto-Escuela DO, Romero-Fernandez W, Garriga P, Ciruela F, Narvaez M, Tarakanov AO et al. (2013). G protein-coupled receptor heterodimerization in the brain. Methods Enzymol 521: 281-294.

Borroto-Escuela DO, Romero-Fernandez W, Tarakanov AO, Ciruela F, Agnati LF, Fuxe K (2011a). On the existence of a possible A2A-D2-beta-Arrestin2 complex: A2A agonist modulation of D2 agonist-induced beta-arrestin2 recruitment. $\mathrm{J} \mathrm{Mol}$ Biol 406: 687-699.

Borroto-Escuela DO, Romero-Fernandez W, Tarakanov AO, Gomez-Soler M, Corrales F, Marcellino D et al. (2010d). Characterization of the A2AR-D2R interface: focus on the role of the C-terminal tail and the transmembrane helices. Biochem Biophys Res Commun 402: 801-807.

Borroto-Escuela DO, Romero-Fernandez W, Tarakanov AO, Marcellino D, Ciruela F, Agnati LF et al. (2010e). Dopamine D2 and 5-hydroxytryptamine 5-HT(A) receptors assemble into functionally interacting heteromers. Biochem Biophys Res Commun 401: 605-610.

Borroto-Escuela DO, Tarakanov AO, Guidolin D, Ciruela F, Agnati LF, Fuxe K (2011b). Moonlighting characteristics of $G$ protein-coupled receptors: focus on receptor heteromers and relevance for neurodegeneration. IUBMB Life 63: 463472. The moonlighting concept is applied for the first time to the GPCR heteroreceptor complexes, since they can carry out different types of functions. Moonlighting of the receptor protomers is the result of dynamic allosteric receptor-receptor and receptor-protein interactions.

Bouvier M, Heveker N, Jockers R, Marullo S, Milligan G (2007). BRET analysis of GPCR oligomerization: newer does not mean better. Nat Methods 4: 3-4. author reply 4.

Breton B, Sauvageau E, Zhou J, Bonin H, Le Gouill C, Bouvier M (2010). Multiplexing of multicolor bioluminescence resonance energy transfer. Biophys $J$ 99: 4037-4046.

Buljan M, Bateman A (2009). The evolution of protein domain families. Biochem Soc Trans 37(Pt 4): 751-755.

Cabello N, Gandia J, Bertarelli DC, Watanabe M, Lluis C, Franco R et al. (2009). Metabotropic glutamate type 5, dopamine D2 and adenosine A2a receptors form higher-order oligomers in living cells. J Neurochem 109: 1497-1507. The combination of bimolecular fluorescence complementation and bioluminescence resonance energy transfer techniques allowed to detect higher order heteroreceptor complexes

Callen L, Moreno E, Barroso-Chinea P, Moreno-Delgado D, Cortes A, Mallol J et al. (2012). Cannabinoid receptors CB1 and CB2 form functional heteromers in brain. J Biol Chem 287: 20851-20865.

Canals M, Marcellino D, Fanelli F, Ciruela F, De Benedetti P, Goldberg SR et al. (2003). Adenosine A2A-dopamine D2 receptor-receptor heteromerization: qualitative and quantitative assessment by fluorescence and bioluminescence energy transfer. J Biol Chem 278: 46741-46749. Fluorescence resonance energy transfer (FRET) and bioluminescence resonance energy transfer (BRET) techniques give strong support to the existence of A2A-D2 receptor heteromers in living cells.
Carlezon WA Jr., Thome J, Olson VG, Lane-Ladd SB, Brodkin ES, Hiroi N et al. (1998). Regulation of cocaine reward by CREB. Science 282: 2272-2275.

Carlsson A (1988). The current status of the dopamine hypothesis of schizophrenia. Neuropsychopharmacology 1: 179-186.

Carlsson A, Fuxe K, Ungerstedt $U$ (1968). The effect of imipramine on central 5hydroxytryptamine neurons. J Pharm Pharmacol 20: 150-151.

Carlsson A, Lindqvist M (1963). Effect of chlorpromazine or haloperidol on formation of 3 methoxytyramine and normetanephrine in mouse brain. Acta pharmacologica et toxicologica 20: 140-144.

Carriba P, Navarro G, Ciruela F, Ferre S, Casado V, Agnati L et al. (2008). Detection of heteromerization of more than two proteins by sequential BRET-FRET. Nat Methods 5: 727-733.

Castren E, Voikar V, Rantamaki T (2007). Role of neurotrophic factors in depression. Curr Opin Pharmacol 7: 18-21.

Ciruela F, Burgueno J, Casado V, Canals M, Marcellino D, Goldberg SR et al. (2004). Combining mass spectrometry and pull-down techniques for the study of receptor heteromerization. Direct epitope-epitope electrostatic interactions between adenosine A2A and dopamine D2 receptors. Anal Chem 76: 53545363. It is the first report showing that epitope-epitope electrostatic interaction can underlie receptor heteromerization.

Ciruela F, Fernandez-Duenas V, Llorente J, Borroto-Escuela D, Cuffi ML, Carbonell L et al. (2012). G protein-coupled receptor oligomerization and brain integration: focus on adenosinergic transmission. Brain Res 1476: 86-95.

Ciruela F, Vilardaga JP, Fernandez-Duenas V (2010). Lighting up multiprotein complexes: lessons from GPCR oligomerization. Trends Biotechnol 28: 407-415.

Cochran AG (2000). Antagonists of protein-protein interactions. Chem Biol 7: R85-R94.

Coyle JT, Duman RS (2003). Finding the intracellular signaling pathways affected by mood disorder treatments. Neuron 38: 157-160.

Chabre M, le Maire M (2005). Monomeric G-protein-coupled receptor as a functional unit. Biochemistry 44: 9395-9403.

Charney DSN, Eric J (2008). Neurobiology of Mental Illness. 3rd edn. Oxford University Press: Oxford1504 pp.

Chen JF, Moratalla R, Yu L, Martin AB, Xu K, Bastia E et al. (2003). Inactivation of adenosine $A 2 A$ receptors selectively attenuates amphetamine-induced behavioral sensitization. Neuropsychopharmacology 28: 1086-1095.

Chiang MC, Lee YC, Huang CL, Chern Y (2005). cAMP-response element-binding protein contributes to suppression of the A2A adenosine receptor promoter by mutant Huntingtin with expanded polyglutamine residues. J Biol Chem 280: $14331-14340$

D'Sa C, Duman RS (2002). Antidepressants and neuroplasticity. Bipolar Disorders 4: 183-194.

Daniels DJ, Kulkarni A, Xie Z, Bhushan RG, Portoghese PS (2005). A bivalent ligand (KDAN-18) containing delta-antagonist and kappa-agonist pharmacophores bridges delta2 and kappa1 opioid receptor phenotypes. J Med Chem 48: 1713-1716.

Diaz-Cabiale Z, Hurd Y, Guidolin D, Finnman UB, Zoli M, Agnati LF et al. (2001). Adenosine A2A agonist CGS 21680 decreases the affinity of dopamine D2 receptors for dopamine in human striatum. Neuroreport 12: 1831-1834.

Dixon RA, Kobilka BK, Strader DJ, Benovic JL, Dohlman HG, Frielle T et al. (1986). Cloning of the gene and cDNA for mammalian beta-adrenergic receptor and homology with rhodopsin. Nature 321: 75-79. Through cloning of the gene and CDNA of the beta2-adrenergic receptor and its homology with rhodopsin the discovery of the GPCR superfamily is made.

Duman RS (2002a). Pathophysiology of depression: the concept of synaptic plasticity. Eur Psychiatry 17(Suppl 3): 306-310.

Duman RS (2002b). Structural alterations in depression: cellular mechanisms underlying pathology and treatment of mood disorders. CNS spectrums 72: 144-147.

Durieux PF, Bearzatto B, Guiducci S, Buch T, Waisman A, Zoli M et al. (2009). D2R striatopallidal neurons inhibit both locomotor and drug reward processes. Nat Neurosci 12: 393-395.

Everitt BJ, Belin D, Economidou D, Pelloux Y, Dalley JW, Robbins TW (2008). Review: Neural mechanisms underlying the vulnerability to develop compulsive drug-seeking habits and addiction. Philos Trans R Soc Lond B Biol Sci 363: 3125-3135.

Faraone D, Aguzzi MS, Ragone G, Russo K, Capogrossi MC, Facchiano A (2006). Heterodimerization of FGF-receptor 1 and PDGF-receptor-alpha: a novel mechanism underlying the inhibitory effect of PDGF-BB on FGF-2 in human cells. Blood 107: 1896-1902.

Farde L, Wiesel FA, Halldin C, Sedvall G (1988). Central D2-dopamine receptor occupancy in schizophrenic patients treated with antipsychotic drugs. Arch Gen Psychiatry 45: 71-76.

Fernandez-Duenas V, Gomez-Soler M, Jacobson KA, Santhosh Kumar T, Fuxe K, Borroto-Escuela DO et al. (2012). Molecular determinants of $a(2 a) r-d(2)$ 
$r$ allosterism: role of the intracellular loop 3 of the $d(2) r$. J Neurochem 123 373-384.

Ferre S, Baler R, Bouvier M, Caron MG, Devi LA, Durroux T et al. (2009). Building a new conceptual framework for receptor heteromers. Nat Chem Biol 5: 131-134.

Ferre S, von Euler G, Johansson B, Fredholm BB, Fuxe K (1991). Stimulation of high-affinity adenosine A2 receptors decreases the affinity of dopamine D2 receptors in rat striatal membranes. Proc Natil Acad Sci USA 88: 7238-7241.

Filip M, Frankowska M, Zaniewska M, Przegalinski E, Muller CE, Agnati L et al. (2006). Involvement of adenosine A2A and dopamine receptors in the locomotor and sensitizing effects of cocaine. Brain Res 1077: 67-80.

Filip M, Zaniewska M, Frankowska M, Wydra K, Fuxe K (2012). The importance of the adenosine $A(2 A)$ receptor-dopamine $D(2)$ receptor interaction in drug addiction. Current Med Chem 19: 317-355.

Flajolet M, Wang Z, Futter M, Shen W, Nuangchamnong N, Bendor J et al. (2008). FGF acts as a co-transmitter through adenosine $\mathrm{A}(2 \mathrm{~A})$ receptor to regulate synaptic plasticity. Nat Neurosci 11: 1402-1409. A direct physical interaction between the A2A and FGF receptors has been discovered of high relevance for synaptic plasticity.

Fotiadis D, Jastrzebska B, Philippsen A, Muller DJ, Palczewski K, Engel A (2006). Structure of the rhodopsin dimer: a working model for G-protein-coupled receptors. Curr Opin Struct Biol 16: 252-259.

Frankowska M, Marcellino D, Adamyck P, Filip M, Fuxe K (2012). Effects of cocaine self-administration and withdrawal on D2-like and A2A receptor recognition and D2-like/Gi protein coupling in rat striatum. Addict Biol 18: 455-466.

Fuxe K (1970). Biological and pharmacological theories discussionBobon DP, Janssen PAJ, Bobon J (eds) The Neuroleptics. S. KargerBasel, Switzerlandpp $121-122$.

Fuxe K, Agnati LF (1985). Receptor-receptor interactions in the central nervous system. A new integrative mechanism in synapses. Med Res Rev 5: 441-482The first review written on the discovery of receptor-receptor interactions. It underlines its role in integration of signals and in drug development.

Fuxe K, Agnati LF, Benfenati F, Celani M, Zini I, Zoli M et al. (1983). Evidence for the existence of receptor-receptor interactions in the central nervous system. Studies on the regulation of monoamine receptors by neuropeptides. J Neural Transm Supp/ 18: 165-179. The term receptor-receptor interactions is used for the first time to describe the neuropeptide modulation of monoamine receptors in membrane preparations. This term was not allowed to be used in 1981 (Acta physiol scand).

Fuxe K, Agnati LF, Jacobsen K, Hillion J, Canals M, Torvinen M et al. (2003). Receptor heteromerization in adenosine A2A receptor signaling: relevance for striatal function and Parkinson's disease. Neurology 61(Suppl 6): S19-S23.

Fuxe K, Agnati LF, Von Euler G, Benfenati F, Zoli M, Härfstrand A et al. (1989). Receptor-receptor interactions and development of psychoative drugs. In: Costa E (ed) Neurochemical Pharmacology- A tribute to B.B.Brodie. Raven Press: New York, USA, pp 211-227.

Fuxe K, Borroto-Escuela DO, Marcellino D, Romero-Fernandez W, Frankowska M, Guidolin D et al. (2012). GPCR heteromers and their allosteric receptor-receptor interactions. Curr Med Chem 19: 356-363.

Fuxe K, Canals M, Torvinen M, Marcellino D, Terasmaa A, Genedani S et al. (2007a). Intramembrane receptor-receptor interactions: a novel principle in molecular medicine. J Neural Transmiss 114: 49-75. Intramembrane receptor-receptor interactions in heteroreceptor complexes represent a novel principle for molecular medicine exemplified on the nervous, endocrine, cardiovascular and immune systems

Fuxe K, Dahlstrom A, Hoistad M, Marcellino D, Jansson A, Rivera A et al. (2007b). From the Golgi-Cajal mapping to the transmitter-based characterization of the neuronal networks leading to two modes of brain communication: wiring and volume transmission. Brain Res Rev 55: 17-54. Wiring and volume transmission can become integrated already at the plasma membrane level through receptorreceptor interactions in heteroreceptor complexes.

Fuxe K, Ferre S, Canals M, Torvinen M, Terasmaa A, Marcellino D et al. (2005). Adenosine A2A and dopamine D2 heteromeric receptor complexes and their function. J Mol Neurosci 26: 209-220.

Fuxe K, Ferre S, Snaprud P, von Euler G, Johansson B, Fredholm B (1993). Antagonistic A2A/D2 receptor interactions in the striatum as a basis for adenosine-dopamine interactions for the central nervous system. Drug Dev Res 28: 374-380.

Fuxe K, Ferre S, Zoli M, Agnati LF (1998). Integrated events in central dopamine transmission as analyzed at multiple levels. Evidence for intramembrane adenosine A2A/dopamine D2 and adenosine A1/dopamine D1 receptor interactions in the basal ganglia. Brain Res Brain Res Rev 26: 258-273. This review is the first one to summarize the evidence for the existence of antagonistic A2A-D2 and A1-D1 receptor-receptor interactions in the basal ganglia.
Fuxe K, Marcellino D, Borroto-Escuela DO, Guescini M, Fernandez-Duenas V, Tanganelli $S$ et al. (2010). Adenosine-dopamine interactions in the pathophysiology and treatment of CNS disorders. CNS Neurosci Ther 16: e18-e42.

Fuxe K, Marcellino D, Genedani S, Agnati L (2007c). Adenosine A(2A) receptors, dopamine $\mathrm{D}(2)$ receptors and their interactions in Parkinson's disease. Mov Disord 22: 1990-2017.

Fuxe K, Marcellino D, Guidolin D, Woods AS, Agnati L (2009). Brain receptor mosaics and their intramembrane receptor-receptor interactions: molecular integration in transmission and novel targets for drug development. J Acupunct Meridian Stud 2: 1-25.

Fuxe K, Marcellino D, Guidolin D, Woods AS, Agnati LF (2008a). Heterodimers and receptor mosaics of different types of G-protein-coupled receptors. Physiology 23: 322-332

Fuxe K, Marcellino D, Rivera A, Diaz-Cabiale Z, Filip M, Gago B et al. (2008b). Receptor-receptor interactions within receptor mosaics. Impact on neuropsychopharmacology. Brain Res Rev 58: 415-452.

Gamulin V, Rinkevich B, Schacke H, Kruse M, Muller IM, Muller WE (1994). Cell adhesion receptors and nuclear receptors are highly conserved from the lowest metazoa (marine sponges) to vertebrates. Biol Chem Hoppe Seyler 375 583-588.

Gancedo C, Flores CL (2008). Moonlighting proteins in yeasts. Microbiol Mol Biol Rev 72: 197-210. table of contents.

George SR, Fan T, Xie Z, Tse R, Tam V, Varghese G et al. (2000). Oligomerization of mu- and delta-opioid receptors. Generation of novel functional properties. J Biol Chem 275: 26128-26135. For the first time evidence is given for the interaction of mu- and delta-opioid receptors in heteroreceptor complexes with the generation of novel pharmacology and G protein coupling properties leading to novel strategies for treatment of pain.

George SR, O'Dowd BF (2007). A novel dopamine receptor signaling unit in brain: heterooligomers of D1 and D2 dopamine receptors. Scientific World J 7: 58-63. The work on their discovery of the D1-D2 heteroreceptor complex is summarized. George and O'Dowd show that the D1-D2 heteroreceptor complex directly links the action of dopamine to rapid calcium signaling which likely has important effects on dopamine-mediated synaptic plasticity.

George SR, O'Dowd BF, Lee SP (2002). G-protein-coupled receptor oligomerization and its potential for drug discovery. Nat Rev Drug Discov 1: 808-820. This is the first review exploring how homoreceptor and heteroreceptor complexes give a new dimension to rational drug design.

Gomes I, Gupta A, Filipovska J, Szeto HH, Pintar JE, Devi LA (2004). A role for heterodimerization of $\mathrm{mu}$ and delta opiate receptors in enhancing morphine analgesia. Proc Natil Acad Sci USA 101: 5135-5139.

Gonzalez-Maeso J, Ang RL, Yuen T, Chan P, Weisstaub NV, Lopez-Gimenez JF et al. (2008). Identification of a serotonin/glutamate receptor complex implicated in psychosis. Nature 452: 93-97. Evidence is provided that a 5-HT2A-mGlu2 heteroreceptor complex may contribute to dysfunctional cortical processes of schizophrenia. This hetero- receptor complex may be a novel target for antipsychotic drugs.

Groenewegen HJ (1988). Organization of the afferent connections of the mediodorsal thalamic nucleus in the rat, related to the mediodorsal-prefrontal topography. Neuroscience 24: 379-431.

Guidolin D, Ciruela F, Genedani S, Guescini M, Tortorella C, Albertin G et al. (2010). Bioinformatics and mathematical modelling in the study of receptor-receptor interactions and receptor oligomerization: focus on adenosine receptors. Biochimica et biophysica acta 1808: 1267-1283.

Guo W, Urizar E, Kralikova M, Mobarec JC, Shi L, Filizola M et al. (2008). Dopamine D2 receptors form higher order oligomers at physiological expression levels. EMBO J 27: 2293-2304.

Gupta A, Mulder J, Gomes I, Rozenfeld R, Bushlin I, Ong E et al. (2010). Increased abundance of opioid receptor heteromers after chronic morphine administration. Sci Signal 3: ra54.

Gurevich W, Gurevich EV (2008a). GPCR monomers and oligomers: it takes all kinds. Trends Neurosci 31: 74-81.

Gurevich W, Gurevich EV (2008b). How and why do GPCRs dimerize? Trends Pharmacol Sci 29: 234-240.

Hague C, Lee SE, Chen Z, Prinster SC, Hall RA, Minneman KP (2006). Heterodimers of alpha1B- and alpha1D-adrenergic receptors form a single functional entity. Mol Pharmacol 69: 45-55.

Halazy S, Perez M, Fourrier C, Pallard I, Pauwels PJ, Palmier C et al. (1996). Serotonin dimers: application of the bivalent ligand approach to the design of new potent and selective 5-HT(1B/1D) agonists. J Med Chem 39: 4920-4927.

Hasbi A, O'Dowd BF, George SR (2011). Dopamine D1-D2 receptor heteromer signaling pathway in the brain: emerging physiological relevance. $\mathrm{Mol}$ Brain 4: 26 
Hauser RA (2011). Future treatments for Parkinson's disease: surfing the PD pipeline. Int J Neurosci 121(Suppl 2): 53-62.

Hauser RA, Hubble JP, Truong DD (2003). Randomized trial of the adenosine $\mathrm{A}(2 \mathrm{~A})$ receptor antagonist istradefylline in advanced PD. Neurology 61: 297-303.

Hauser RA, Schwarzschild MA (2005). Adenosine A2A receptor antagonists for Parkinson's disease: rationale, therapeutic potential and clinical experience. Drugs Aging 22: 471-482.

Hern JA, Baig AH, Mashanov Gl, Birdsall B, Corrie JE, Lazareno S et al. (2010). Formation and dissociation of $\mathrm{M} 1$ muscarinic receptor dimers seen by total internal reflection fluorescence imaging of single molecules. Proc Natl Acad Sci USA 107: 2693-2698.

Hodgson RA, Bedard PJ, Varty GB, Kazdoba TM, Di Paolo T, Grzelak ME et al. (2010). Preladenant, a selective $A(2 A)$ receptor antagonist, is active in primate models of movement disorders. Exp Neurol 225: 384-390.

Horger BA, Wellman PJ, Morien A, Davies BT, Schenk S (1991). Caffeine exposure sensitizes rats to the reinforcing effects of cocaine. Neuroreport 2: 53-56.

Huberts DH, van der Klei IJ (2010). Moonlighting proteins: an intriguing mode of multitasking. Biochimica et biophysica acta 1803: 520-525.

Jaakola VP, Griffith MT, Hanson MA, Cherezov V, Chien EY, Lane JR et al. (2008). The 2.6 angstrom crystal structure of a human A2A adenosine receptor bound to an antagonist. Science 322: 1211-1217.

Jacob F (1977). Evolution and tinkering. Science 196: 1161-1166.

James JR, Oliveira MI, Carmo AM, laboni A, Davis SJ (2006). A rigorous experimental framework for detecting protein oligomerization using bioluminescence resonance energy transfer. Nat Methods 3: 1001-1006.

Jeffery CJ (1999). Moonlighting proteins. Trends Biochem Sci 24: 8-11. The concept of moonlighting proteins is introduced.

Jeffery CJ (2004). Molecular mechanisms for multitasking: recent crystal structures of moonlighting proteins. Current opinion in structural biology 14 : 663-668.

Jentsch JD, Roth RH (1999). The neuropsychopharmacology of phencyclidine: from NMDA receptor hypofunction to the dopamine hypothesis of schizophrenia. Neuropsychopharmacology 20: 201-225.

Jin MS, Kim SE, Heo JY, Lee ME, Kim HM, Paik SG et al. (2007). Crystal structure of the TLR1-TLR2 heterodimer induced by binding of a tri-acylated lipopeptide. Cell 130: 1071-1082

Kenakin T, Agnati LF, Caron M, Fredholm B, Guidoli D, Kobilka B et al. (2010). International Workshop at the Nobel Forum, Karolinska Institutet on G proteincoupled receptors: finding the words to describe monomers, oligomers, and their molecular mechanisms and defining their meaning. Can a consensus be reached? J Receptor Signal Transduction Res 30: 284-286.

Knapp CM, Foye MM, Cottam N, Ciraulo DA, Kornetsky C (2001). Adenosine agonists CGS 21680 and NECA inhibit the initiation of cocaine self-administration. Pharmacol Biochem Behav 68: 797-803.

Knebel W, Rao N, Uchimura T, Mori A, Fisher J, Gastonguay MR et al. (2011). Population pharmacokinetic-pharmacodynamic analysis of istradefylline in patients with Parkinson disease. J Clin Pharmacol 52: 1468-1481.

Kobe B, Kajava AV (2001). The leucine-rich repeat as a protein recognition motif. Curr Opin Struct Biol 11: 725-732.

Lambert NA (2010). GPCR dimers fall apart. Sci Signal 3: pe12.

Landschulz WH, Johnson PF, McKnight SL (1988). The leucine zipper: a hypothetical structure common to a new class of DNA binding proteins. Science 240: 1759-1764.

Laruelle M, Abi-Dargham A, van Dyck CH, Gil R, D'Souza CD, Erdos J et al. (1996). Single photon emission computerized tomography imaging of amphetamineinduced dopamine release in drug-free schizophrenic subjects. Proc Natl Acad Sci USA 93: 9235-9240.

Lee FJ, Pei L, Liu F (2009). Disruption of the dopamine transporter-dopamine D2 receptor interaction in schizophrenia. Synapse 63: 710-712.

Lee FJ, Xue S, Pei L, Vukusic B, Chery N, Wang Y et al. (2002). Dual regulation of NMDA receptor functions by direct protein-protein interactions with the dopamine D1 receptor. Cell 111: 219-230. The discovery of the D1-NMDA heteroreceptor complex and its regulation is made.

Lee FS, Chao MV (2001). Activation of Trk neurotrophin receptors in the absence of neurotrophins. Proc Natl Acad Sci USA 98: 3555-3560.

Lee SP, O'Dowd BF, George SR (2003). Homo- and hetero-oligomerization of G protein-coupled receptors. Life Sci 74: 173-180. Receptor oligomerization is proposed to represent a pivotal aspect of the structure and function of GPCRs.

Lee SP, So CH, Rashid AJ, Varghese G, Cheng R, Lanca AJ et al. (2004). Dopamine D1 and D2 receptor Co-activation generates a novel phospholipase C-mediated calcium signal. J Biol Chem 279: 35671-35678. This paper gives the first evidence for the existence of a D1-D2 heteroreceptor complex leading to Gq coupling and a novel type of signaling.
Lefkowitz RJ (2000). The superfamily of heptahelical receptors. Nat Cell Biol 2: E133-E136. The first review of the close structural relationship between the beta2-adrenergic recptor and rhodopsin leading to the discovery of the GPCR superfamily.

Li J, Edwards PC, Burghammer M, Villa C, Schertler GF (2004). Structure of bovine rhodopsin in a trigonal crystal form. J Mol Biol 343: 1409-1438.

Li S, Chen S, Wang YT, Liu F (2011). Disrupting protein complexes using Tat-tagged peptide mimics. Methods Mol Biol 756: 381-393.

Liu XY, Chu XP, Mao LM, Wang M, Lan HX, Li MH et al. (2006). Modulation of D2RNR2B interactions in response to cocaine. Neuron 52: 897-909. A direct D2RNR2B interaction is discovered in postsynaptic density microdomains of glutamate synapses.

Lukasiewicz S, Polit A, Kedracka-Krok S, Wedzony K, Mackowiak M, DziedzickaWasylewska M (2010). Hetero-dimerization of serotonin 5-HT(2A) and dopamine $\mathrm{D}(2)$ receptors. Biochimica et biophysica acta 1803: 1347-1358.

Luttrell LM, Daaka Y, Lefkowitz RJ (1999). Regulation of tyrosine kinase cascades by G-protein-coupled receptors. Curr Opin Cell Biol 11: 177-183.

Mallei A, Shi B, Mocchetti I (2002). Antidepressant treatments induce the expression of basic fibroblast growth factor in cortical and hippocampal neurons. Mol Pharmacol 61: 1017-1024.

Manji HK, Duman RS (2001). Impairments of neuroplasticity and cellular resilience in severe mood disorders: implications for the development of novel therapeutics. Psychopharmacol Bullet 35: 5-49.

Maragnoli ME, Fumagalli F, Gennarelli M, Racagni G, Riva MA (2004). Fluoxetine and olanzapine have synergistic effects in the modulation of fibroblast growth factor 2 expression within the rat brain. Biol Psychiatry 55: 1095-1102.

Marcellino D, Carriba P, Filip M, Borgkvist A, Frankowska M, Bellido I et al. (2008). Antagonistic cannabinoid CB1/dopamine D2 receptor interactions in striatal CB1/D2 heteromers. A combined neurochemical and behavioral analysis. Neuropharmacology 54: 815-823.

Marcellino D, Roberts DC, Navarro G, Filip M, Agnati L, Lluis C et al. (2007). Increase in A2A receptors in the nucleus accumbens after extended cocaine selfadministration and its disappearance after cocaine withdrawal. Brain Res 1143: 208-220.

Marshall FH, White J, Main M, Green A, Wise A (1999). GABA(B) receptors function as heterodimers. Biochem Soc Trans 27: 530-535.

Marullo S, Bouvier M (2007). Resonance energy transfer approaches in molecular pharmacology and beyond. Trends Pharmacol Sci 28: 362-365.

Mattson BJ, Bossert JM, Simmons DE, Nozaki N, Nagarkar D, Kreuter JD et al. (2005). Cocaine-induced CREB phosphorylation in nucleus accumbens of cocaine-sensitized rats is enabled by enhanced activation of extracellular signalrelated kinase, but not protein kinase A. J Neurochem 95: 1481-1494.

Meltzer HY, Massey BW (2011). The role of serotonin receptors in the action of atypical antipsychotic drugs. Curr Opin Pharmacol 11: 59-67.

Milligan G, Smith NJ (2007). Allosteric modulation of heterodimeric G-proteincoupled receptors. Trends Pharmacol Sci 28: 615-620.

Milligan G, White JH (2001). Protein-protein interactions at G-protein-coupled receptors. Trends Pharmacol Sci 22: 513-518.

Morelli M, Blandini F, Simola N, Hauser RA (2012). A(2A) Receptor Antagonism and Dyskinesia in Parkinson's Disease. Parkinsons Dis 2012: 489853.

Morelli M, Di Paolo T, Wardas J, Calon F, Xiao D, Schwarzschild MA (2007). Role of adenosine A2A receptors in parkinsonian motor impairment and I-DOPA-induced motor complications. Prog Neurobiol 83: 293-309.

Moreno JL, Muguruza C, Umali A, Mortillo S, Holloway T, Pilar-Cuellar F et al. (2012). Identification of three residues essential for 5-hydroxytryptamine 2Ametabotropic glutamate 2 (5-HT2A.mGlu2) receptor heteromerization and its psychoactive behavioral function. J Biol Chem 287: 44301-44319.

Morgan D, Brebner K, Lynch WJ, Roberts DC (2002). Increases in the reinforcing efficacy of cocaine after particular histories of reinforcement. Behav Pharmacol 13: 389-396.

Muguruza C, Moreno JL, Umali A, Callado LF, Meana JJ, Gonzalez-Maeso J (2012). Dysregulated 5-HT(2A) receptor binding in postmortem frontal cortex of schizophrenic subjects. Eur Neuropsychopharmacol 23: 852-864.

Nakata H, Yoshioka K, Kamiya T, Tsuga H, Oyanagi K (2005). Functions of heteromeric association between adenosine and P2Y receptors. J Mol Neurosci 26: 233-238.

Nestler EJ, Gould E, Manji H, Buncan M, Duman RS, Greshenfeld HK et al. (2002). Preclinical models: status of basic research in depression. Biol Psychiatry 52: 503-528.

Nguyen JT, Turck CW, Cohen FE, Zuckermann RN, Lim WA (1998). Exploiting the basis of proline recognition by $\mathrm{SH} 3$ and WW domains: design of $\mathrm{N}$-substituted inhibitors. Science 282: 2088-2092.

O'Dowd BF, Ji X, Nguyen T, George SR (2011). Two amino acids in each of D1 and D2 dopamine receptor cytoplasmic regions are involved in D1-D2 heteromer formation. Biochem Biophys Res Commun 417: 23-28l. 
Electrostatic interactions between the intracellular loop 3 of the D2 receptor (two adjacent arginine residues) and the carboxyl tail of the D1 receptor (two adjacent glutamic acid residues) play a crucial role in the D1-D2 receptor interface.

O'Dowd BF, Ji X, O'Dowd PB, Nguyen T, George SR (2012). Disruption of the mu-delta opioid receptor heteromer. Biochem Biophys Res Commun 422: 556-560. In the intracellular loop 3 of both mu and delta opioid receptors there exists an aminoacid triplet SVR, which when substituted in any of its residues prevents the formation of the heteroreceptor complex.

Ogren SO, Rosen L, Fuxe K (1994). The dopamine D2 antagonist remoxipride acts in vivo on a subpopulation of dopamine D2 receptors. Neuroscience 61 269-283.

Pancer Z, Kruse M, Muller I, Muller WE (1997). On the origin of Metazoan adhesion receptors: cloning of integrin alpha subunit from the sponge Geodia cydonium. Mol Biol Evol 14: 391-398

Patil ST, Zhang L, Martenyi F, Lowe SL, Jackson KA, Andreev BV et al. (2007). Activation of mGlu2/3 receptors as a new approach to treat schizophrenia: a randomized Phase 2 clinical trial. Nat Med 13: 1102-1107.

Pawson T, Gish GD, Nash P (2001). SH2 domains, interaction modules and cellular wiring. Trends Cell Biol 11: 504-511.

Pawson T, Scott JD (1997). Signaling through scaffold, anchoring, and adaptor proteins. Science 278: 2075-2080.

Perez M, Jorand-Lebrun C, Pauwels PJ, Pallard I, Halazy S (1998). Dimers of 5HT1 ligands preferentially bind to 5HT1B/1D receptor subtypes. Bioorg Med Chem Lett 8: 1407-1412.

Pin JP, Neubig R, Bouvier M, Devi L, Filizola M, Javitch JA et al. (2007). International Union of Basic and Clinical Pharmacology. LXVII. Recommendations for the recognition and nomenclature of $\mathrm{G}$ protein-coupled receptor heteromultimers. Pharmacol Rev 59: 5-13.

Popken GJ, Bunney WE Jr, Potkin SG, Jones EG (2000). Subnucleus-specific loss of neurons in medial thalamus of schizophrenics. Proc Natl Acad Sci USA 97 9276-9280.

Popoli P, Betto P, Reggio R, Ricciarello G (1995). Adenosine A2A receptor stimulation enhances striatal extracellular glutamate levels in rats. Euro $J$ Pharmacol 287: 215-217.

Popoli P, Pezzola A, Torvinen M, Reggio R, Pintor A, Scarchilli L et al. (2001). The selective mGlu(5) receptor agonist CHPG inhibits quinpirole-induced turning in 6hydroxydopamine-lesioned rats and modulates the binding characteristics of dopamine $\mathrm{D}(2)$ receptors in the rat striatum: interactions with adenosine $A(2 a)$ receptors. Neuropsychopharmacology 25: 505-513.

Rajkowska G, Miguel-Hidalgo JJ, Wei J, Dilley G, Pittman SD, Meltzer HY et al. (1999). Morphometric evidence for neuronal and glial prefrontal cell pathology in major depression. Biol Psychiatry 45: 1085-1098.

Rashid AJ, O'Dowd BF, Verma V, George SR (2007a). Neuronal Gq/11-coupled dopamine receptors: an uncharted role for dopamine. Trends Pharmacol Sci 28 551-555

Rashid AJ, So CH, Kong MM, Furtak T, El-Ghundi M, Cheng R et al. (2007b). D1-D2 dopamine receptor heterooligomers with unique pharmacology are coupled to rapid activation of $\mathrm{Gq} / 11$ in the striatum. Proc Natl Acad Sci USA 104: 654-659.

Ritter SL, Hall RA (2009). Fine-tuning of GPCR activity by receptor-interacting proteins. Nat Rev Mol Cell Biol 10: 819-830.

Romero-Fernandez W, Borroto-Escuela DO, Agnati LF, Fuxe K (2012). Evidence for the existence of dopamine d2-oxytocin receptor heteromers in the ventral and dorsal striatum with facilitatory receptor-receptor interactions. Mol Psychiatry 18 : 849-850.

Romero-Fernandez W, Borroto-Escuela DO, Tarakanov AO, Mudo G, Narvaez M, Perez-Alea $\mathrm{M}$ et al. (2011). Agonist-induced formation of FGFR1 homodimers and signaling differ among members of the FGF family. Biochem Biophys Res Commun 409: 764-768.

Rozenfeld R, Devi LA (2010). Receptor heteromerization and drug discovery. Trends Pharmacol Sci 31: 124-130.

Saarelainen T, Hendolin P, Lucas G, Koponen E, Sairanen M, MacDonald E et al. (2003). Activation of the TrkB neurotrophin receptor is induced by antidepressant drugs and is required for antidepressant-induced behavioral effects. J Neurosci 23: 349-357.

Schmidt HD, Duman RS (2007). The role of neurotrophic factors in adult hippocampal neurogenesis, antidepressant treatments and animal models of depressive-like behavior. Behav Pharmacol 18: 391-418.

Schwartz JC, Diaz J, Pilon C, Sokoloff P (2000). Possible implications of the dopamine $\mathrm{D}(3)$ receptor in schizophrenia and in antipsychotic drug actions. Brain Res Brain Res Rev 31: 277-287.

Schwarzschild MA, Agnati L, Fuxe K, Chen JF, Morelli M (2006). Targeting adenosine A2A receptors in Parkinson's disease. Trends in Neurosci 29: 647-654.
Seeman P (2006). Targeting the dopamine D2 receptor in schizophrenia. Expert Opin Ther Targets 10: 515-531.

Self DW (2010). Dopamine receptor subtypes in Reward and relapse. In: Neve KA (eds) The dopamine receptors 2010/07/21edn (Humana Press: Portland, pp 479-524.

Shen HY, Coelho JE, Ohtsuka N, Canas PM, Day YJ, Huang QY et al. (2008). A critical role of the adenosine $\mathrm{A} 2 \mathrm{~A}$ receptor in extrastriatal neurons in modulating psychomotor activity as revealed by opposite phenotypes of striatum and forebrain A2A receptor knock-outs. J Neurosci 28: 2970-2975.

Shirayama Y, Chen AC, Nakagawa S, Russell DS, Duman RS (2002). Brain-derived neurotrophic factor produces antidepressant effects in behavioral models of depression. J Neurosci 22: 3251-3261.

Soderberg O, Gullberg M, Jarvius M, Ridderstrale K, Leuchowius KJ, Jarvius J et al. (2006). Direct observation of individual endogenous protein complexes in situ by proximity ligation. Nat Methods 3: 995-1000.

Soria G, Castane A, Ledent C, Parmentier M, Maldonado R, Valverde O (2006). The lack of A2A adenosine receptors diminishes the reinforcing efficacy of cocaine. Neuropsychopharmacology 31: 978-987.

Soriano A, Ventura R, Molero A, Hoen R, Casado V, Cortes A et al. (2009). Adenosine A2A receptor-antagonist/dopamine D2 receptor-agonist bivalent ligands as pharmacological tools to detect A2A-D2 receptor heteromers. J Med Chem 52: 5590-5602.

Spanagel R, Weiss F (1999). The dopamine hypothesis of reward: past and current status. Trends Neurosci 22: 521-527.

Stromberg I, Popoli P, Muller CE, Ferre S, Fuxe K (2000). Electrophysiological and behavioural evidence for an antagonistic modulatory role of adenosine A2A receptors in dopamine D2 receptor regulation in the rat dopamine-denervated striatum. Eur J Neurosci 12: 4033-4037.

Surmeier DJ (2007). Calcium, ageing, and neuronal vulnerability in Parkinson's disease. Lancet Neurol 6: 933-938.

Svensson TH (2000). Dysfunctional brain dopamine systems induced by psychotomimetic NMDA-receptor antagonists and the effects of antipsychotic drugs. Brain Res Brain Res Rev 31: 320-329.

Tanganelli S, Sandager Nielsen K, Ferraro L, Antonelli T, Kehr J, Franco R et al. (2004). Striatal plasticity at the network level. Focus on adenosine A2A and D2 interactions in models of Parkinson's Disease. Parkinsonism Relat Disord 10: 273-280.

Tarakanov AO, Fuxe KG (2010). Triplet puzzle: homologies of receptor heteromers. $\mathrm{J}$ Mol Neurosci 41: 294-303. A set of triplet aminoacid homologies has been deduced that may be involved in receptor-receptor interactions and be part of the receptor interface. Such triplets of amino acid residues and their 'teams' may be utilized to construct a kind of code that help determine which receptors should form heterodimers. A 'uide-and-clasp' manner for receptor-receptor interactions is proposed where 'adhesive guides' may be represented by the triplet amino acid homologies.

Tarakanov AO, Fuxe KG (2011a). The triplet puzzle of homologies in receptor heteromers exists also in other types of protein-protein interactions. J Mol Neurosci 44: 173-177.

Tarakanov AO, Fuxe KG, Borroto-Escuela DO (2011b). On the origin of the triplet puzzle of homologies in receptor heteromers: immunoglobulin triplets in different types of receptors. J Mol Neurosci 46: 616-621.

Tarakanov AO, Fuxe KG, Borroto-Escuela DO (2012a). Integrin triplets of marine sponges in human brain receptor heteromers. J Mol Neurosci 48: 154-160.

Tarakanov AO, Fuxe KG, Borroto-Escuela DO (2012b). Integrin triplets of marine sponges in human D2 receptor heteromers. J Receptor Signal Transduct Res 32 202-208.

Tarakanov AO, Fuxe KG, Borroto-Escuela DO (2012c). On the origin of the triplet puzzle of homologies in receptor heteromers: Toll-like receptor triplets in different types of receptors. J Neural Transmiss 119: 517-523.

Torvinen M, Marcellino D, Canals M, Agnati LF, Lluis C, Franco R et al. (2005). Adenosine A2A receptor and dopamine D3 receptor interactions: evidence of functional A2A/D3 heteromeric complexes. Mol Pharmacol 67: 400-407.

Trifilieff P, Rives ML, Urizar E, Piskorowski RA, Vishwasrao HD, Castrillon $\mathrm{J}$ et al. (2011). Detection of antigen interactions ex vivo by proximity ligation assay: endogenous dopamine D2-adenosine A2A receptor complexes in the striatum. BioTechniques 51: 111-118. This excellent method paper adapted and optimized a proximity ligation assay (PLA) for the detection in brain slices of molecular proximity of two antigens located on two different GPCRs. Using this approach, it became possible to confirm and extend the existence of dopamine D2 and adenosine A2A receptor complexes in the striatum of mice ex vivo.

Turner CA, Akil H, Watson SJ, Evans SJ (2006). The fibroblast growth factor system and mood disorders. Biol Psychiatry 59: 1128-1135.

Urizar E, Yano H, Kolster R, Gales C, Lambert N, Javitch JA (2011). CODA-RET reveals functional selectivity as a result of GPCR heteromerization. Nat Chem Biol 7: 624-630. 
Vilardaga JP, Agnati LF, Fuxe K, Ciruela F (2010). G-protein-coupled receptor heteromer dynamics. J Cell Sci 123(Pt 24): 4215-4220.

Vorel SR, Ashby CR Jr., Paul M, Liu X, Hayes R, Hagan JJ et al. (2002). Dopamine D3 receptor antagonism inhibits cocaine-seeking and cocaine-enhanced brain reward in rats. J Neurosci 22: 9595-9603.

Vortherms TA, Watts VJ (2004). Sensitization of neuronal A2A adenosine receptors after persistent D2 dopamine receptor activation. J Pharmacol Exp Ther 308: 221-227.

Weerts EM, Griffiths RR (2003). The adenosine receptor antagonist CGS15943 reinstates cocaine-seeking behavior and maintains self-administration in baboons. Psychopharmacology 168: 155-163.

White JF, Grodnitzky J, Louis JM, Trinh LB, Shiloach J, Gutierrez J et al. (2007). Dimerization of the class A G protein-coupled neurotensin receptor NTS1 alters G protein interaction. Proc Natl Acad Sci USA 104: 12199-12204.
Wise RA (2009). Roles for nigrostriatal-not just mesocorticolimbic-dopamine in reward and addiction. Trends Neurosci 32: 517-524.

Wong DT, Bymaster FP, Engleman EA (1995). Prozac (fluoxetine, Lilly 110140), the first selective serotonin uptake inhibitor and an antidepressant drug: twenty years since its first publication. Life sciences 57: 411-441.

Woods AS, Marcellino D, Jackson SN, Franco R, Ferre S, Agnati LF et al. (2008). How calmodulin interacts with the adenosine $A(2 A)$ and the dopamine D(2) receptors. J Proteome Res 7: 3428-3434. Mass spectrometric analysis indicates that an electrostatic interaction involving the D2 receptor Arg-rich epitope and several $\mathrm{CaM}$ acidic epitopes are mainly responsible for the $\mathrm{D} 2$ receptor-CaM binding. The results indicate a dynamic role of calmodulin in modulating the A2A-D2 receptor-receptor interaction. 